\title{
The evolution of health outcomes from childhood to adolescence
}

\author{
Paul Contoyannis
}

Jinhu Li

contoyp@mcmaster.ca

lij53@mcmaster.ca

Department of Economics, McMaster University

\begin{abstract}
Using data from the Canadian National Longitudinal Survey of Children and Youth (NLSCY), this study examines how and why health outcomes exhibit persistence during the period from childhood to adolescence. We examine the distribution of health outcomes and health transitions using descriptive analysis and explore the determinants of these distributions by estimating the contributions of family SES, unobserved heterogeneity and state dependence and also allowing for heterogeneity of state dependence parameters across categories of neighborhood status. Our analysis indicates that children living in poorer neighborhoods and in neighborhoods with lower education level tend to experience poor health status for longer after a transition to it, while children tend to experience multiple health drops living in poorer neighborhoods, in neighborhoods with less educated people, in neighborhoods with more families headed by lone-parents and in neighborhoods with more families living in rental accommodations.
\end{abstract}

Keywords: child health; health dynamics; Canadian panel data; neighbourhood effects

Paper presented at Conference on Health over the Life Course, University of Western Ontario, London, Ontario, 14-16 October 2009 


\title{
The evolution of health outcomes from childhood to adolescence
}

\author{
Paul Contoyannis ${ }^{\mathrm{a} *}$
}

Jinhu $\mathrm{Li}^{\mathrm{b}}$

Preliminary Draft

September 25, 2009

\begin{abstract}
Using data from the Canadian National Longitudinal Survey of Children and Youth (NLSCY), this study examines how and why health outcomes exhibit persistence during the period from childhood to adolescence. We examine the distribution of health outcomes and health transitions using descriptive analysis and explore the determinants of these distributions by estimating the contributions of family SES, unobserved heterogeneity and state dependence and also allowing for heterogeneity of state dependence parameters across categories of neighborhood status. Our analysis indicates that children living in poorer neighborhoods and in neighborhoods with lower education level tend to experience poor health status for longer after a transition to it, while children tend to experience multiple health drops living in poorer neighborhoods, in neighborhoods with less educated people, in neighborhoods with more families headed by lone-parents and in neighborhoods with more families living in rental accommodations.
\end{abstract}

Keywords: child health; health dynamics; Canadian panel data; neighbourhood effects

JEL classification: C5; I12

\footnotetext{
a*_Corresponding Author: Department of Economics, McMaster University, Kenneth Taylor Hall, Rm 416, 1280 Main Street West, Hamilton, Ontario, Canada L8S 4M4. E-mail: contoyp@mcmaster.ca: Tel:1-905-525-9140x26582, Fax:1-905-546-5211

b Department of Economics, McMaster University, Kenneth Taylor Hall, Rm 426, 1280 Main Street West, Hamilton, Ontario, Canada L8S 4M4. E-mail: lij53@mcmaster.ca
} 


\section{Introduction}

Health development during the period of childhood to adolescence is important because, for most individuals, initial health in adulthood and attitudes towards health promoting or risky behaviors are largely formed during this transition period (see e.g. Heckman 2006). Furthermore, evidence documents that pre-adult health is positively correlated with achievement over the lifespan (see e.g. Case et al 2005). While the association of child/youth health and economic, institutional and environmental factors has been examined by various studies within a static framework, few studies have focused explicitly on health dynamics from childhood to adolescence. On both efficiency and equity grounds, it is important to quantify both the mobility and persistence of health over time and to identify systematic differences in mobility across subgroups. Knowing the systematic differences in the dynamics of health across different subgroups helps to disentangle how different factors determine the health transition from childhood to adolescence within a population. Furthermore, if we observe that reductions in health status are more permanent than transitory in nature for particular groups, we may be more concerned about this than cross-sectional variation in health; more efficient improvement of average health status of the whole population can be made possible if social support programs are targeted at individuals who are more likely to have multiple periods of ill-health and equity objectives likely require us to be more concerned about children who suffer prolonged ill health.

This study draws on two streams of health outcomes research. The first stream focuses on the association of child/youth health and economic, institutional and contextual factors. A positive relationship between high family SES and good child health status has been recorded in various studies. Using cross-sectional data sets of U.S children, Case et al. (2002) pointed out children's health is positively related to household income and the income-health gradient has deepened as children age. They also investigated the extent to which the gradient can be explained by other characteristics of children and parents, including child health at birth, parental health, genetic ties, health insurance and maternal labor supply. Following Case et al. (2002), Currie and Stabile (2003) used the Canadian NLSCY to confirm the deepening gradient, and to test two hypotheses of the underlying mechanisms that cause the deepening gradient. They concluded that the mechanism of the deepening gradient is not that children with poorer health lack the resources to respond to health shocks, but they are subject to more shocks. Curtis et al. (2001) explored data from the Ontario Child Health Study (OCHS) to estimate the association between child health and both low-income and family status. They find that child health is much more strongly (and negatively) related to low-average-income than to low-current income, while lone-mother status is negatively associated with child outcomes. Another two studies have provided evidence of the health-SES gradients among adolescents (Graeme Fort et al. 1994, Chris Power and Sharon Matthews 1997). The above examples largely identified the potential SES factors that are correlated with and may contribute to the health of children and adolescents. However, it is worth mentioning that few of these studies are implemented in a panel data framework and dealt with individual unobserved heterogeneity. The only study we are aware of which involves the transition of health outcomes from childhood to adolescence is Currie and Stabile (2003). However, it has a different focus from our investigation and was implemented in a different empirical framework. In order to test one of the two hypotheses in explaining the deepening SES-health gradient recorded by Case et al. (2002), they investigated whether low-SES children deal with bad "health shocks" as effectively as high-SES children by examining if the negative impacts of previous chronic conditions onset differ by family SES. While their results are in line with ours in the sense that poor health status in the previous period has persistent negative effects on current child health, the study did not focus on how state dependence systematically determine the dynamics of child health over time and how state dependence of child health differ across neighborhood types as in our study. In their study, only two periods of data are used and the onset of chronic conditions in the first period are controlled as the "health shocks" for health state in the second period; while in our study all six cycles are used and self-assessed health status in the previous period is controlled for in modeling current self-assessed health status. 
The positive association between SES and health is difficult to untangle for adults, due to the likelihood of a reverse causal relationship. Although the channel that runs directly from health to income can be eliminated for the case of children, possible unobserved factors that can affect child health outcomes and are also correlated with family SES make identification of a causal relationship difficult. Dooley and Stewart (2004) used data from the Canadian NLSCY and cautiously estimated the size of the effect of income on child's cognitive outcomes by attempting to separate out the variation in outcomes caused by potential unobserved heterogeneity and that caused by regressors. They implemented four empirical strategies and reported a smaller income effect on child outcomes than from conventional estimates which are obtained from weighted least squares regressions with pooled data. This difference in estimates reveals the benefit of exploiting a panel data structure when unobserved individual heterogeneity contributes substantially to child outcomes.

Other studies have focused on the social contextual influences on child outcomes. Boyle et al. (2007) used multilevel models to examine longitudinal associations between contextual influences (neighborhood and family) and educational attainment in a cohort of 2,355 children. The results showed that while $33.64 \%$ of the variation in individual level educational attainment can be explained by their model, $14.53 \%$ of the variation is attributable to neighborhood and family-level variables versus $10.94 \%$ to child-level variables. Several other studies have provided consistent evidence that neighborhood or community level socioeconomic advantage is positively associated with better child outcomes (Brooks-Gunn, Duncan, Klebanov and Sealand 1993; Garner and Raudenbush 1991). Leventhal and Brooks-Gunn (2000) provide a comprehensive review of research on the effects of neighborhood residence on child and adolescent well-being. By summarizing the existing evidence of neighborhood effects on child and youth outcomes, they conclude that high SES is of great importance for school readiness and achievement while low SES and residential instability are determinants of poor behavioral/emotional outcomes. Therefore, social contextual or environmental characteristics should be considered as other important factors related to child and youth health.

The second stream of studies on health outcomes focuses on modeling adult health distributions in a dynamic framework. Studies have addressed the question of why some adults experience persistently good or bad health. The persistence could be explained by pure state dependence, particular individual socio-economic characteristics, or environmental characteristics (Jones, Rice and Contoyannis 2006). Some empirical health dynamics studies have examined the relative contributions of pure state dependence and unobserved heterogeneity, and the conditional effect of socio-economic status in explaining observed health status variation (Contoyannis, Jones and Rice 2004a, Contoyannis, Jones and Rice 2004b), while other empirical health dynamics studies have provided evidence of associations between observed health persistence and SES positions. In particular using the British Household Panel Survey (BHPS), Hauck and Rice (2004) found evidence of substantial mental health mobility and that the extent of mobility varies across SES categories with greatest persistence in lower income groups and less educated individuals. In a different framework, Buckley et al. (2004) examined the influence of SES position on transition probabilities from good health to poor health for older Canadians. The results showed that the probability of remaining in good health is higher in the highest quartile of income and education, which also indicated a positive association between good health and SES.

Our study aims to contribute in the following ways. Firstly, this study contributes to the health dynamics and child health literature. As discussed above few studies have been focused on modeling the evolution process of health outcome from childhood to adolescence, particularly in Canada. Secondly, as this paper uses information on both family SES positions and neighborhood level characteristics into the dynamic panel data framework, it contributes by examining the impact of contextual factors in the health dynamics literature.

This paper proceeds as follows. Section 2 describes the data set we used for the study and presents 
some descriptive analysis of the data. Section 3 introduces the theoretical rationale and empirical framework of the study. In section 4, the regression results are reported and analysed while in section 5 some conclusions are provided.

\section{Data}

As this study considers both the effects of family SES positions and neighbourhood characteristics on child health dynamics, two data sets are explored in our study. The first data set is the Canadian National Longitudinal Survey of Children and Youth (NLSCY) cycles 1 to 6, which contains rich information on child outcomes and family SES positions. The second data set is the Census profile data of Canada 1996 and 2001, which contains information on neighborhood characteristics. We construct and use the following four sets of variables throughout this study: 1) child health outcome measures, e.g. Self-Assessed Health (SAH) of the child reported by the Person Most Knowledgeable(PMK) about this child; 2) family socio-economic variables, e.g. total household income, parental education, family structure (family size, whether the child is living with two parents) etc.; 3) Other variables for the child and the parents such as age, whether the PMK is the biological parent of the child and maternal age at birth of the child; 4) neighborhood level variables, indicating the "affluence" status and "socioeconomic disadvantage" status of the neighborhoods, e.g. mean household income, percentage of population with university degree, etc.

\subsection{Sample and variables}

The National Longitudinal Survey of Children and Youth (NLSCY) is the main data source used in this study to examine the contribution of family SES positions in determining health transitions. The NLSCY is a survey "designed to collect detailed information every two years about the factors influencing a child's cognitive, emotional and physical development and to monitor the impact of these factors over time" (NLSCY user guide). With the main purpose of following up a group of children over time, the survey began to collect information with one large cohort of 0-11 year- olds in 1994, and followed up every two years till 2004 (Cycle 6). All the available waves so far (from Cycle 1 to Cycle 6) are used in this study. For children younger than 18, the primary respondent for the questions related to the child is the person most knowledgeable (PMK) about the child in the household, while for those older than 18 the respondent for questions is the person themselves. The survey also collects information for the PMK and the spouse of the PMK about their age, education, labor force participation and health condition etc. From this information, the family structure and parental characteristics with potential impacts on child's health development are extracted.

With respect to child health, the variable of general health assessed by the PMK or the child himself/herself is used in the analysis. The survey question requires the respondent to rank the child's health as excellent, very good, good, fair or poor. The child health measure is confined to this variable only for this study. In order to investigate the relationship between family SES and child health outcomes we use the total household income in the past 12 months and a set of variables for parental educational achievements. Case et al. 2002 found that while there still exists a large and significant correlation between income and child's health, the addition of parental education levels to the regression controls had a substantial impact on the estimated income coefficients (reducing the magnitude of the positive correlation). This suggests that household income and parental education are two important factors in determining the child's health and they affect child's health through different pathways. In the NLSCY, information about educational attainment, labor force participation etc. are collected for the PMK and the spouse of PMK, but the PMK and the spouse of PMK are not necessarily the biological parents of the child. They can be step parents, adopting parents or even unrelated persons. This brings in complexity in interpretation because mother's education may influence child health through both her childcare skills after birth and the health of the child at birth, while a PMK who is not the mother will likely exert a much larger influence(relative to the birth mother) on child health through childcare. Moreover, mother's education and father's education level 
are expected to have different impacts on child's health in that, in most cases, it is the mother who takes care of the child and their behavior would shape child's health to a larger extent, especially for the children at younger ages. Therefore, we separate mother's education from father's education level. In this study, mother's education was obtained from the PMK's (or the spouse of PMK) education level if PMK (or the spouse of PMK) is the biological mother of the child. Otherwise, female caregiver education was obtained from the closest female figure in the household (defining the biological mother as the closest female figure overall), i.e. it was obtained from the information of the PMK (or the spouse of PMK) if PMK (or the spouse of PMK) is female but not the biological mother of the child. If there is no education information for the closest adult female figure in the household, female caregiver education was set to missing. The variable for male caregiver education was derived in the same way. In order to capture the difference between the effects of education for a biological mother and another female figure, a dummy indicating the PMK (or spouse of the PMK) is the biological mother of the child is included in the regression and interacted with mother's education level. Also, a dummy indicating PMK is female is included in the regression to account for the response "bias" by gender. Other than the main SES variables, family structure characteristics have a potential impact on child health. A variable for family size indicating the total number of persons living in the household and a dummy variable indicating whether or not a child lives with both parents are included in the regression too. Table 1 lists the definitions of the main variables we used in this study.

Table 1. Variable names and definitions

\begin{tabular}{ll}
\hline Variable Name & \\
\hline $\begin{array}{l}\text { hlthc } \\
\text { child age } \\
\text { child gender } \\
\text { family size }\end{array}$ & $\begin{array}{l}\text { Health status of child, } 5 \text { categories: excellent, very good, good, fair and poor } \\
\text { Airthage }\end{array}$ \\
$\begin{array}{l}\text { Gender of child(Male=1) } \\
\text { hh income } \\
\text { schoolm }\end{array}$ & Age of mother at birth of the child \\
& Household income \\
& Female caregiver education, 1= less than secondary, 2=secondary school \\
schoolf & g=some post-secondary, 4=college or university degree \\
& Male caregiver education, 1= less than secondary, 2=secondary school graduation, \\
PMKnm & 3=some post-secondary, 4=college or university degree \\
PMKfe & Dummy indicating PMK not biological mother \\
twopar & Dummy indicating PMK if female \\
area & Dummy indicating child living with two parents \\
& Province of residence \\
\hline
\end{tabular}

To explore the relationship between neighborhood characteristics and child health dynamics, we split our sample by a set of neighborhood level variables indicating the "affluence" status and "socioeconomic disadvantage" status of the neighborhood the child resides in. In our study, "neighborhood" is defined by census tract (CT) boundaries within all census metropolitan areas (CMAs) and part of census agglomerations (CAs) where a CT boundary exists, while by Enumeration Area (EA) or dissemination areas (DAs) boundaries within more rural areas where a CT boundary does not exist. Census tracts (CTs) are small geographic units representing urban or rural neighborhood-like communities within all CMAs and CAs with an urban core population of 50,000 or more at the previous census. In most CTs, there are 2,500-8,000 people living within them (Statistics Canada, 1992). An EA is the smallest level of geographical aggregation used by Statistics Canada: it contains at least 375 dwellings in urban areas and 125 dwellings in rural areas. To attach neighborhood information to every child in each cycle, we firstly matched the neighborhoods identities within NLSCY and Census profile data through Enumeration Area (EA) or Dissemination 
Area (DA) code which exist in both data sets. Since the neighborhoods are mostly defined by CT boundaries, we then used the Geography Tape File (GTF) to map from EA/DA boundaries to CT boundaries when CT boundaries are used to define neighborhoods. At the end, the neighborhood variables aggregated at the CT boundary level are used for the neighborhoods defined by CTs; while the neighborhood variables aggregated at the EA or DA boundary level are used for the neighborhoods defined by EAs or DA s. In our study, the "affluence" status of the neighborhoods is measured by two variables: average household income and the percentage of the adult population with university or college degrees; while the "socioeconomic disadvantage" status of the neighborhoods is measured by another two variables: percentage of families headed by lone parents and the percentage of families living in rental accommodations. These specific concepts of community characteristics have been established and used in studies examining the neighborhood influence on educational attainment of children (Boyle et al. 2007). Since we are using a longitudinal cohort and the respondents might have moved from one neighborhood to another across cycles, we mapped the respondents into neighborhoods for each cycle based on the most up-to-date available census profile data at that time. In other words, the neighborhood characteristics are drawn from the census profile data 1996 for the first four cycles of NLSCY, while these values are drawn from the census profile data 2001 for the last two cycles of NLSCY. When we split the sample into subgroups based on the neighborhood characteristics, we divide them into quartiles based on the simple average of a neighborhood variable across 6 cycles. This allows us to include both movers and stayers in our sample and does not restrict classification according to the neighborhood variable at an arbitrary period of time for all individuals (e.g cycle 1).

\subsection{Data description}

Several sample selection criteria have been used for the investigation of family SES and child health dynamics association in our study. Firstly, we only included children who had information with respect to all of our main variables in all six cycles. Only a balanced panel sample is used for both descriptive and regression analysis. Secondly, we excluded children with very unreasonable records in their data, e.g. we excluded children who had multiple gender values across cycles. We ended up with 22,398 observations for 3,733 children with 6 time periods. For the subgroup analysis with different neighbourhood types, we then only included children with complete information with respect to the four neighbourhood variables in all six cycles. This leads to a further reduction of sample to 20,040 observations for 3,340 children with 6 time periods.

\subsubsection{The whole sample}

\section{Child SAH}

Originally the health status variable is a categorical variable with 5 ranks. However, we regrouped this variable in the descriptive analysis by merging the fair health group and poor health group because of the constraint imposed by the data confidentiality requirement from Statistics Canada. After the merge, the number of observations in the fair/poor health group is big enough for data disclosure. Figure 1 (see all figures in Appendix A) shows the health dynamics of children over 6 cycles. The proportion of children in excellent health was decreasing and the proportion of children in very good health was increasing slightly between cycles 1 and 3. Between cycles 4 and 6 there does not appear to be a discernible trend in the proportions reporting excellent and very good health. In all cycles there are only a very small proportion of children reported as in fair or poor health with no apparent trend in this proportion or for the proportion in good health. Figure 2 shows the distribution of child's health status by age group at cycle 1 . As age increases, the proportion of children reporting excellent health decreases while the proportion of children reporting very good health increases. The age profile of health distribution can be seen from this figure as well.

Figure 3 displays the distribution of child's health status pooled over 6 cycles by household income 
categories. From the figure, it can be seen that children's health status is better in households with higher incomes than those in households with lower incomes. As we move from low income group to high income groups, the proportion of children in excellent health increases while the proportion of children in fair or poor health decreases.

Figures 4 and 5 display the distribution of child's health status pooled over 6 cycles, by mother's education attainment and the distribution of child's health status pooled over 6 cycles, by father's education attainment respectively. Both of the figures show very similar patterns of child health variation as to parents' income level. The proportion of children with excellent health increases and the proportion of children with fair or poor health decreases as we move up from lower parental education level to higher parental education level.

\section{State Dependence}

State dependence in health has been explored by the literature in health dynamics (e.g Contoyannis et al. 2004) and it is expected to explain a substantial proportion of health variation. Without conditioning on other variables, the degree of mobility/persistence of health outcomes can be assessed descriptively by the probability distribution conditioned on the previous health distribution. Figure 6 shows the distribution of child's health status in cycle 2 by the previous health status in cycle 1 . It can be seen from the figure that given the child was in excellent health in cycle 1, the probability of transiting from excellent health to fair or poor health is very close to zero and the probability of staying in excellent health is very high. Similarly, for the children who had fair or poor health in cycle 1 , the probability of transiting from fair or poor health to excellent health is very low while the probability of staying fair or poor health is high. In general, this figure shows that children are much more likely to stay in their health status of origin than moving away from it. The same pattern can be seen for all the cycles from a transition matrix in table 2. The elements of the table can be interpreted as the conditional probabilities under a Markov model. The table shows that conditioning on being in excellent or very good health states, children are much more likely to stay within the states than moving away from them in the current period; while conditioning on being good health or lower than good health, children are more likely to move one level up in the current period. It indicates that the persistence mainly operates around the state of excellent health and very good health while the health status is pretty mobile around the states of good and fair/poor health.

Table 2. Transition matrix, balanced whole sample

\begin{tabular}{cccccc}
\hline & $\begin{array}{c}\text { Fair/Poor } \\
\mathrm{t}\end{array}$ & $\begin{array}{c}\text { Good } \\
\mathrm{t}\end{array}$ & $\begin{array}{c}\text { Very Good } \\
\mathrm{t}\end{array}$ & $\begin{array}{c}\text { Excellent } \\
\mathrm{t}\end{array}$ \\
\hline Fair/Poor & $\mathrm{t}-1$ & 0.250 & 0.411 & 0.199 & 0.140 \\
Good & $\mathrm{t}-1$ & 0.043 & 0.355 & 0.378 & 0.224 \\
Very Good & $\mathrm{t}-1$ & 0.010 & 0.124 & 0.460 & 0.405 \\
Excellent & $\mathrm{t}-1$ & 0.005 & 0.042 & 0.219 & 0.735 \\
\hline
\end{tabular}

\section{Family SES and other variables}

In order to examine the association between family SES characteristics and child health dynamics, we compared the means of the family SES variables across a set of child health transition scenarios. Tables 3 and 4 present the means for the main family SES and other demographic variables for the whole sample and for a set of interesting sub-samples. Column 1 in table 3 lists the mean values for the whole balanced sample. The second column shows the average characteristics for the children who had excellent or very good health for all 6 cycles and the third column shows the average characteristics for the children who always had less than good health. Column 4 presents the mean values for the children who had a single transition from excellent or very good health to worse health 
status without recovering to the original health status, while column 5 shows the mean of variables for the children who had a single transition from less than good health to better health and stayed healthy since then. From the comparison between the second and third columns, it can be seen that children who were always in excellent or very good health tend to be living in a smaller household and be brought up in a richer family than the children who were always in good or less than good health. Also, mother's age at the birth of the child is lower for the children with excellent health or very good health than for the children with good or less than good health. Surprisingly, there is no systematic difference in the parents' education level for these subgroups. No specific pattern is found comparing the subgroup of children who had a single transition from excellent to very good health and did not recover and the subgroup of children who had a single transition from good to poor health, except that household income and parents' education level are slightly higher for the first subgroup than for the second subgroup.

Table 3. Mean of family SES and other variables

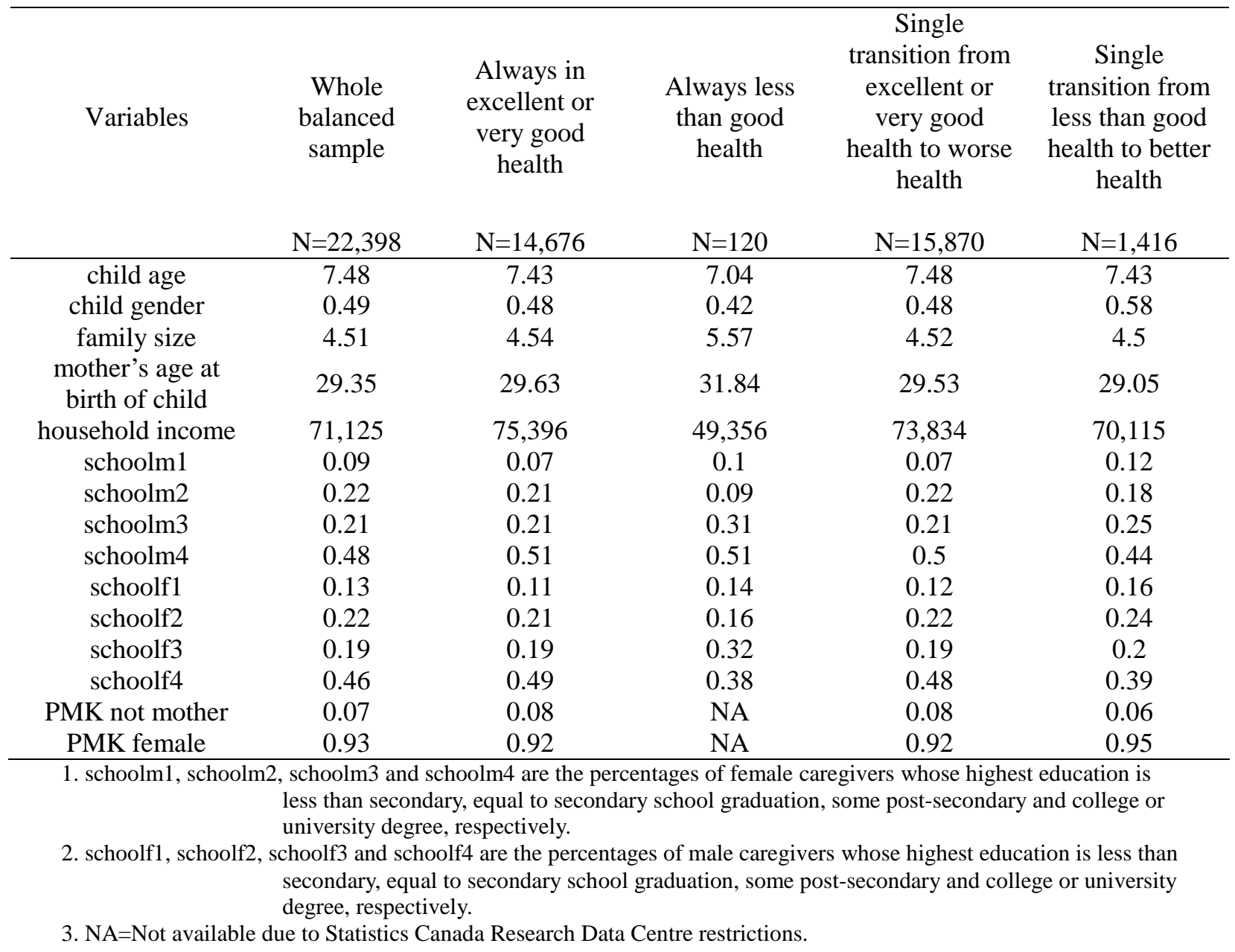

In table 4, we show the mean values of these variables for the subsample of children who had few health drops versus the subsample of children who had multiple drops, and for the subsample of children whose health drop lasted for only 1 cycle versus the subsample of children whose health drop lasted for multiple periods. Columns 1-4 show the mean values for the groups of children who had 0 , $1,2,3$ or 4 drops during our study period, respectively. Children with lower family income and lower parental education tend to experience multiple health drops relative to the children with higher family 
SES. This observation is in line with the result from the study by Currie and Stabile (2003) which indicates that children brought up in families with lower SES are subject to more health shocks than the children with higher family SES. Columns 5-8 show the mean values for the groups of children who had 1 drop and this drop lasted for only 1cycle, for 2 cycles, for 3 cycles and for 4 cycles. A slight negative association is discernable from the comparison among these subsamples, with children who experienced short health drops are brought up in families with slightly higher income. The basic descriptive statistics shows a negative association between family SES and the number of health shocks the children experienced while a much weaker negative association exists between the family SES variables and the persistence of health shocks.

Table 4. Mean of family SES and other variables

\begin{tabular}{|c|c|c|c|c|c|c|c|c|}
\hline Variables & $\begin{array}{l}\text { Had } 0 \\
\text { drop }\end{array}$ & $\begin{array}{c}\text { Had } 1 \\
\text { drop }\end{array}$ & $\begin{array}{l}\text { Had } 2 \\
\text { drops }\end{array}$ & $\begin{array}{c}\text { Had } 3 \text { or } \\
4 \text { drops }\end{array}$ & $\begin{array}{c}\text { Had } 1 \\
\text { drop \& } \\
\text { duration } \\
=1 \text { cycle }\end{array}$ & $\begin{array}{c}\text { Had } 1 \\
\text { drop \& } \\
\text { duration } \\
=2 \\
\text { cycles }\end{array}$ & $\begin{array}{c}\text { Had } 1 \\
\text { drop \& } \\
\text { duration } \\
=3 \\
\text { cycles }\end{array}$ & $\begin{array}{c}\text { Had } 1 \\
\text { drop \& } \\
\text { duration } \\
=4 \\
\text { cycles }\end{array}$ \\
\hline & $\mathrm{N}=6,480$ & $N=9,768$ & $\mathrm{~N}=5,370$ & $N=780$ & $\mathrm{~N}=3,888$ & $\mathrm{~N}=1,248$ & $\mathrm{~N}=522$ & $\mathrm{~N}=174$ \\
\hline child age & 7.53 & 7.44 & 7.47 & 7.63 & 7.3 & 7.39 & 7.07 & 7.16 \\
\hline child gender & 0.48 & 0.49 & 0.5 & 0.54 & 0.55 & 0.49 & 0.43 & 0.53 \\
\hline family size & 4.6 & 4.46 & 4.47 & 4.66 & 4.5 & 4.38 & 4.33 & 4.46 \\
\hline $\begin{array}{l}\text { mother's age at } \\
\text { birth of child }\end{array}$ & 29.66 & 29.35 & 29.03 & 28.78 & 29.26 & 29.17 & 30.58 & 31.35 \\
\hline $\begin{array}{l}\text { household } \\
\text { income }\end{array}$ & 81,649 & 69,959 & 61,824 & 59,616 & 71,719 & 68,053 & 66,493 & 67,001 \\
\hline schoolm1 & 0.06 & 0.1 & 0.12 & 0.18 & 0.08 & 0.08 & 0.05 & 0.25 \\
\hline schoolm2 & 0.2 & 0.22 & 0.25 & 0.22 & 0.19 & 0.19 & 0.18 & 0.25 \\
\hline schoolm3 & 0.23 & 0.21 & 0.2 & 0.21 & 0.21 & 0.21 & 0.3 & 0.16 \\
\hline schoolm4 & 0.52 & 0.48 & 0.43 & 0.38 & 0.52 & 0.52 & 0.47 & 0.34 \\
\hline schoolf1 & 0.09 & 0.13 & 0.17 & 0.21 & 0.12 & 0.11 & 0.09 & 0.25 \\
\hline schoolf2 & 0.21 & 0.22 & 0.23 & 0.15 & 0.19 & 0.25 & 0.17 & 0.18 \\
\hline schoolf3 & 0.18 & 0.21 & 0.17 & 0.19 & 0.2 & 0.21 & 0.28 & 0.14 \\
\hline schoolf4 & 0.52 & 0.45 & 0.42 & 0.45 & 0.48 & 0.43 & 0.46 & 0.43 \\
\hline PMK not mother & 0.09 & 0.07 & 0.07 & 0.06 & 0.07 & 0.05 & 0.06 & 0.04 \\
\hline PMK female & 0.92 & 0.93 & 0.93 & 0.94 & 0.93 & 0.95 & 0.94 & 0.96 \\
\hline
\end{tabular}

\subsubsection{Sub-samples by “affluence” and "socioeconomic disadvantage” status of neighbourhood}

\section{State Dependence}

Another goal of this study is to identify which neighbourhood characteristics contribute to the persistence of poor health states. For the subgroup analysis, we divide the whole sample into four subgroups for each of the four neighbourhood characteristics variables and constructed the transition matrices for each subgroup. We can see some general patterns over a set of transition matrices presented in table 5. The first panel of table 5 shows, the transition matrices for neighborhoods with lowest, second lowest, middle and highest levels of average household income, respectively. It shows that the less than good health state is more persistent in lower income neighborhoods than in higher income neighborhoods. In particular, in the highest income neighborhoods children with less than good health in the last period are most likely to move up one rank, while in the lowest income neighborhoods they are most likely to continue to have less than good health. The second panel shows the transition matrices for neighborhoods with less educated people and for neighborhoods with more 
educated people. Being in the less than good health state is more persistent in neighborhoods with less educated people than in neighborhoods with more educated people. The third panel presents the transition matrices for neighborhoods with larger proportions of families headed by lone-parents and for neighborhoods with smaller proportions of families head by lone-parents. The last panel shows the transition matrices for neighborhoods with larger proportions of families living in rental accommodations with smaller proportions of families living in rental accommodations. The similar pattern in these four panels indicates that, without conditioning on any other variables, the persistence level of ill health is different across neighborhoods with different income levels. In particular, the ill health state is more mobile in neighborhoods with higher income, in neighborhoods with more educated people, in neighborhoods with fewer families headed by lone-parents and in neighborhoods with fewer families living in rental accommodations. 
Table 5. Transition matrices by neighborhood status

By quartiles of mean household income of neighbourhood

\begin{tabular}{|c|c|c|c|c|c|c|c|c|c|c|c|c|c|c|c|}
\hline \multicolumn{4}{|c|}{ Lowest income } & \multicolumn{4}{|c|}{ Second lowest income } & \multicolumn{4}{|c|}{ Middle income } & \multicolumn{4}{|c|}{ Highest income } \\
\hline & $\begin{array}{c}< \\
\text { Good }\end{array}$ & $\begin{array}{l}\text { Very } \\
\text { Good }\end{array}$ & Ex & & $\begin{array}{c}< \\
\text { Good }\end{array}$ & $\begin{array}{l}\text { Very } \\
\text { Good }\end{array}$ & Ex & & $\begin{array}{c}< \\
\text { Good }\end{array}$ & $\begin{array}{l}\text { Very } \\
\text { Good }\end{array}$ & Ex & & $\begin{array}{c}< \\
\text { Good }\end{array}$ & $\begin{array}{l}\text { Very } \\
\text { Good }\end{array}$ & Ex \\
\hline$<$ Good & 0.483 & 0.321 & 0.196 & $<$ Good & 0.49 & 0.34 & 0.171 & $<$ Good & 0.449 & 0.276 & 0.276 & $<$ Good & 0.332 & 0.459 & 0.209 \\
\hline Very Good & 0.124 & 0.47 & 0.407 & Very Good & 0.174 & 0.503 & 0.323 & Very Good & 0.126 & 0.441 & 0.434 & Very Good & 0.12 & 0.442 & 0.439 \\
\hline Excellent & 0.058 & 0.274 & 0.668 & Excellent & 0.052 & 0.227 & 0.722 & Excellent & 0.052 & 0.235 & 0.713 & Excellent & 0.035 & 0.172 & 0.793 \\
\hline
\end{tabular}

By quartiles of proportion of population with university degree in neighbourhood

\begin{tabular}{|c|c|c|c|c|c|c|c|c|c|c|c|c|c|c|c|}
\hline \multicolumn{4}{|c|}{ Lowest \% with college degree } & \multicolumn{4}{|c|}{ Second lowest \% } & \multicolumn{4}{|c|}{ Second highest \% } & \multicolumn{4}{|c|}{ Highest \% with college degree } \\
\hline & $\begin{array}{c}< \\
\text { Good }\end{array}$ & $\begin{array}{l}\text { Very } \\
\text { Good }\end{array}$ & Ex & & $\begin{array}{c}< \\
\text { Good }\end{array}$ & $\begin{array}{l}\text { Very } \\
\text { Good }\end{array}$ & Ex & & $\begin{array}{c}< \\
\text { Good }\end{array}$ & $\begin{array}{l}\text { Very } \\
\text { Good }\end{array}$ & Ex & & $\begin{array}{c}< \\
\text { Good }\end{array}$ & $\begin{array}{l}\text { Very } \\
\text { Good }\end{array}$ & Ex \\
\hline$<$ Good & 0.458 & 0.34 & 0.203 & $<$ Good & 0.441 & 0.327 & 0.233 & $<$ Good & 0.458 & 0.319 & 0.222 & $<$ Good & 0.378 & 0.433 & 0.19 \\
\hline Very Good & 0.147 & 0.451 & 0.402 & Very Good & 0.16 & 0.446 & 0.394 & Very Good & 0.13 & 0.449 & 0.421 & Very Good & 0.111 & 0.49 & 0.399 \\
\hline Excellent & 0.054 & 0.233 & 0.713 & Excellent & 0.064 & 0.23 & 0.706 & Excellent & 0.045 & 0.235 & 0.721 & Excellent & 0.035 & 0.185 & 0.78 \\
\hline
\end{tabular}

\begin{tabular}{|c|c|c|c|c|c|c|c|c|c|c|c|c|c|c|c|}
\hline \multicolumn{4}{|c|}{ Highest \% with lone-parents } & \multicolumn{4}{|c|}{ Second highest \% } & \multicolumn{4}{|c|}{ Second lowest \% } & \multicolumn{4}{|c|}{ Lowest \% with lone-parents } \\
\hline & $\begin{array}{c}< \\
\text { Good }\end{array}$ & $\begin{array}{c}\text { Very } \\
\text { Good }\end{array}$ & Ex & & $\begin{array}{c}< \\
\text { Good }\end{array}$ & $\begin{array}{l}\text { Very } \\
\text { Good }\end{array}$ & Ex & & $\begin{array}{c}< \\
\text { Good }\end{array}$ & $\begin{array}{c}\text { Very } \\
\text { Good }\end{array}$ & Ex & & $\begin{array}{c}< \\
\text { Good }\end{array}$ & $\begin{array}{l}\text { Very } \\
\text { Good }\end{array}$ & Ex \\
\hline$<$ Good & 0.532 & 0.309 & 0.16 & $\mathrm{~d}$ & 0.391 & 0.364 & 0.246 & $<\mathrm{G}$ & 0.413 & 0.338 & 0.249 & $<$ Good & 0.351 & 0.424 & 0.225 \\
\hline Very Good & 0.145 & 0.478 & 0.377 & ood & 0.139 & 0.44 & 0.421 & ood & 0.1 & 0.456 & 5 & ood & 0.154 & 0.469 & 0.377 \\
\hline Excellent & 0.051 & 0.263 & 0.687 & Excellent & 0.05 & 0.185 & 0.764 & Excellent & 0.041 & 0.202 & 0.757 & Excellent & 0.043 & 0.218 & 0.739 \\
\hline
\end{tabular}

By quartiles of proportion of families living in rental accommodations in neighborhood

\begin{tabular}{|c|c|c|c|c|c|c|c|c|c|c|c|c|c|c|c|}
\hline \multicolumn{4}{|c|}{$\begin{array}{l}\text { Highest \% with rental } \\
\text { accommodations }\end{array}$} & \multicolumn{4}{|c|}{ Second highest \% } & \multicolumn{4}{|c|}{ Second lowest \% } & \multicolumn{4}{|c|}{$\begin{array}{l}\text { Lowest \% with rental } \\
\text { accommodations }\end{array}$} \\
\hline & $\begin{array}{c}<< \\
\text { Good }\end{array}$ & $\begin{array}{l}\text { Very } \\
\text { Good }\end{array}$ & Ex & & $\begin{array}{c}< \\
\text { Good }\end{array}$ & $\begin{array}{l}\text { Very } \\
\text { Good }\end{array}$ & Ex & & $\begin{array}{c}< \\
\text { Good }\end{array}$ & $\begin{array}{l}\text { Very } \\
\text { Good }\end{array}$ & Ex & & $\begin{array}{c}< \\
\text { Good }\end{array}$ & $\begin{array}{l}\text { Very } \\
\text { Good }\end{array}$ & Ex \\
\hline$<$ Good & 0.498 & 0.314 & 0.188 & $<$ Good & 0.457 & 0.343 & 0.2 & $<$ Good & 0.371 & 0.384 & 0.245 & $<$ Good & 0.382 & 0.384 & 0.234 \\
\hline Very Good & 0.127 & 0.476 & 0.397 & Very Good & 0.152 & 0.424 & 0.424 & ery Good & 0.138 & 0.456 & 0.406 & Very Good & 0.121 & 0.486 & 0.393 \\
\hline Excellent & 0.055 & 0.228 & 0.717 & Excellent & 0.041 & 0.209 & 0.749 & Excellent & 0.042 & 0.214 & 0.744 & Excellent & 0.044 & 0.208 & 0.748 \\
\hline
\end{tabular}




\section{Empirical Methods}

A widely used economic model (Currie 2000) for child health determination will be followed in this study. In the standard model, parents are assumed to maximize an intertemporal utility function, which trades off child's health stock and their consumption of other goods and leisure, subject to a series of budget and time constraints. The solution to the maximization problem gives the demand function for child health stock. Unfortunately we do not know the health production function which makes it impossible to specify the complete structural model and, in any case, it is difficult to estimate convincingly. Therefore, an alternative representation is used instead in which child health outcomes depend on a set of family SES factors (mainly family income, family structure), child characteristics, parental characteristics and some initial conditions such as maternal age at birth.

Empirically, this study will examine the effects on child health outcomes of SES position, neighbourhood characteristics, pure state dependence and unobserved heterogeneity. Taking into account neighbourhood characteristics is expected to reduce estimates of unobserved heterogeneity. State dependence will be taken into account by controlling for the lag of the health status of the child, while unobserved heterogeneity will be controlled for by using random effects models. Previous empirical studies have been implemented using either pooled approaches or dynamic nonlinear panel data approach with random effects (Contoyannis et al. 2004a, b, Hauck and Rice 2004). This is because, with a nonlinear fixed effect model, the MLE estimator is not consistent in a panel setting with small $\mathrm{T}$ (\# of time periods) and large $\mathrm{N}$ (\# of individuals), due to the incidental parameters problem from estimating the fixed effects.

As in most of the micro-level panel data cases, our data is a short panel of large cross-sections (large $\mathrm{N}$ but small $\mathrm{T}$ ). Econometricians have attempted to find fixed- $\mathrm{T}$ consistent estimators in modelling discrete choices with individual effects but, in general, fixed-T consistent estimators for nonlinear panel models are not available for most models with unobserved heterogeneity treated as fixed effects. As in static models, there is a trade-off between choosing fixed and random effects approaches for the dynamic nonlinear panel data models we consider in this study, in the sense that achieving fixed-T identification with a less restricted conditional distribution of individual effects usually requires a more restrictive specification of the conditional distribution for $y$ given variables of interest and individual effects.(e.g. logit type)

Fixed effects models are more robust without imposing restrictions on the conditional distribution of individual effects but it suffers from the incidental parameter problem. There are no general solutions for nonlinear models with fixed effects, and in some cases, although a specific solution is available, it is not root-N-consistent. For example a dynamic logit fixed T- consistent estimator is available but it converges slowly and does not allow for time dummies. (see Honore and Tamer 2006).

Arellano (2003) pointed out that there are random effects models that achieve fixed T consistency subject to a particular specification of the form of the dependence between the explanatory variables and the effects, but they rely on strong and untestable auxiliary assumptions. For example, the random effects dynamic nonlinear panel data approach advocated by Woodridge (2005), which is one of the approaches we implement in our study, can generate consistent estimators only when the specified distribution of the individual effects is correct. Even though fixed T consistency is achievable for less restrictive random effects specifications, identification is often out of reach (see Honore and Tamer 2006).

\subsection{Baseline dynamic panel ordered probit model without individual effects}

A basic approach to estimating the effect of family SES variables in explaining the health transition is to estimate a dynamic panel model without dealing with individual specific effects at all. We denote 
this the pooled model. The regression model can be simply specified as below:

$$
H_{i t}^{*}=\theta^{\prime} H_{i t-1}+\beta^{\prime} X_{i t}+\varepsilon_{i t} \quad(\mathrm{i}=1, \ldots, \mathrm{N} ; \mathrm{t}=2, \ldots, \mathrm{T})
$$

where $H_{i t} *$ is the latent variable of health outcome, $H_{i t-1}$ is a vector of indicators for the child's health status in the previous period, $X_{i t}$ is a set of observed family SES variables. $\varepsilon_{i t}$ is a time and individual-specific error term which is assumed to be normally distributed and uncorrelated across individuals and waves. The latent variable $H_{i t}$ * relates to the observed health outcome $H_{i t}$ as follows:

$$
H_{i t}=j \text { if } \mu_{j-1}<H_{i t}^{*}<\mu_{j}, j=1, \ldots, m
$$

where $\mu_{0}=-\infty, \mu_{j} \leq \mu_{j+1}, \mu_{m}=\infty$.

\subsection{Dynamic panel ordered probit model with random effects}

The empirical specification incorporating the family SES effect and unobserved heterogeneity can be written as:

$$
H_{i t}^{*}=\theta^{\prime} H_{i t-1}+\beta^{\prime} X_{i t}+\alpha_{i}+\varepsilon_{i t} \quad(\mathrm{i}=1, \ldots, \mathrm{N} ; \mathrm{t}=2, \ldots, \mathrm{T})
$$

where $\alpha_{i}$ is an individual-specific and time-invariant random component, and the idiosyncratic component $\varepsilon_{i t}$ is assumed to be uncorrelated with $\alpha_{i}$. The latent variable $H_{i t} *$ specification is the same as in 3.1.1.

This study follows the approach of Wooldridge (Wooldridge 2005), Contoyannis et al. (2004b) which attempts to deal with the initial conditions problem in non-linear dynamic random effects models; the individual specific effect is specified as the following:

$$
\alpha_{i}=\alpha_{0}+\alpha_{1}^{\prime} H_{i 1}+\alpha_{2}^{\prime} \bar{X}_{i}+u_{i}
$$

where $\bar{X}_{i}$ is the average over the sample period of the observations on the time-varying exogenous variables and $u_{i}$ is assumed to be normally distributed.

\section{Estimation Results}

\subsection{Estimation with whole sample}

Table 6 presents the coefficient estimates for the ordered probit models based on pooled and random effects specifications. Column 2 and 3 shows the estimates of coefficients and standard errors with the pooled ordered probit model, while column 4 and 5 show the estimates of coefficients and standard errors with the random effects model with the specification suggested by Wooldridge (2005). The pooled ordered probit models allow for serial correlation in the errors by using a robust estimator of the covariance matrix. Several patterns can be seen from the comparison of the models. Firstly, there is a gradient in the effect of previous health on current health. The reference group here is the group reporting very good health (the second highest rank of health state). For both of the models, previous health is highly statistically significant and the magnitude of the coefficient is not trivial. Secondly, the child's health status does improve as family SES position increases, shown by the significant and positive coefficients on the household income variable and positive gradients on parental education level. In order to capture the differential effects of maternal education on child health through biological and other pre and postnatal effects, the interaction terms of maternal education with the dummy indicating whether the PMK is the biological mother of the child are included in the 
regressions. It can be seen from column 4 and column 5 that after controlling for the within-individual average of current household income and the within-individual average of parental education level, the original current household income variable and parental education variables are not as large and some are no longer statistically significant. This result is in line with the interpretation of regarding the mean income as a measure of long-term or 'permanent' income while regarding current income as a measure of transitory income shocks (Contoyannis et al. 2004 a, b). It shows that the long-term household income, other than the transitory income, is important for the child's health status. Other statistically significant variables are child age, and age of mother at birth of child, and family size. Thirdly, the improvement in the log-likelihood from model (1) to model (2) indicates that allowing for unobserved heterogeneity can improve the goodness-of-fit of the model. Moreover, it can be seen from the ICC value in model (2) that about $31 \%$ of the latent error variance is attributable to unobserved heterogeneity.

As the estimated coefficients for the pooled models are not directly comparable to the ones for the random effects models, we calculated the average partial effects (APEs) on the probability of reporting excellent health. The results are presented in table 7 . The magnitude of state dependence is smaller in the random effects model than the pooled model, highlighting the importance of separating pure state dependence and unobserved individual effects.

An "empirical" transition matrix of reporting each health status given the previous health status is constructed based on the estimates of the random effects model and reported in Table 8. This transition matrix is comparable to Table 2 except that it shows the predicted probabilities conditional on all the control variables.

\subsection{Subsample analysis}

In order to identify whether and how neighbourhood characteristics contribute to the persistence of poor health, we divide the whole sample into quartiles according to each of four neighbourhood characteristics variables. These are the average household income of the neighbourhood, the proportion of the population with a college degree, the proportion of families headed by lone-parents and the proportion of households living in rental accommodation. For each subsample, we estimated a pooled ordered probit model and random effect ordered probit model with the specification suggested by Wooldridge (2005). The corresponding average partial effects (APEs) of reporting excellent health status for the random effects specification are presented in Table 9. The gradient of pure state dependence is observable across all subsamples. "Permanent" household income has significant positive effects on reporting excellent health for all the subgroups, but the magnitudes of the effects indicate different interaction patterns between "permanent" household income and different neighbourhood characteristics. For example, the positive effect of "permanent" household income on child health is stronger in richer neighbourhoods and also more educated neighbourhoods. This shows the average household income level and education level of neighbourhood are positive moderators of a "permanent" family income effect. Parental education has significant positive effects on reporting excellent health for all the subgroups as well, but the neighbourhood characteristics have negative moderating effects on both mother's education and father's education. Parental education always plays a more important role in worse neighbourhoods relative to better neighbourhoods.

The transition matrices of reporting each health status given the previous health status for different types of neighbourhoods are constructed based on the estimates of the random effects model and reported in Table 10. These transition matrices are comparable to the ones in the descriptive analysis except that they are the predicted probabilities conditional on all the control variables. In the table, previous health status is presented in rows while current health status is presented in columns. Like the transition matrices in the descriptive analysis, the low health state is more persistent in neighborhoods with lower income and in neighborhoods with less educated people than in neighborhoods with more educated people. Nonetheless, there is no discernable pattern across neighborhoods with different 
living arrangements and across neighborhoods with different proportions of lone-parents families. It indicates that controlling for family level characteristics it is rather the "affluence" status of neighbourhood than "socioeconomic disadvantage" of neighborhood that contributes to the heterogeneity of persistence levels of ill-health over time.

Furthermore, we calculated the predicted probabilities of health trajectories based on these transition matrices which are comparable to the descriptive results in table 4. Figure 7 shows the predicted probabilities of health drops lasting for only 1 cycle versus health drops lasting for multiple periods across different neighbourhoods. The first panel compares the probabilities across neighbourhoods with different levels of average household income. The second, third and fourth panel compares the probabilities across neighbourhoods with different proportions of highly-educated people, across neighbourhoods with different proportions of lone-parents families and across neighbourhoods with different proportions of families living in rental accommodations. Figure 8 shows the predicted probabilities of children having 0 drop, 1 drop, 2 drops, 3 or 4 drops during 6 cycles across different neighbourhoods. It is observable that children tend to experience multiple health drops living in poorer neighborhoods, in neighborhoods with less educated people, in neighborhoods with more families headed by lone-parents and in neighborhoods with more families living in rental accommodations.

\section{Conclusions}

From the descriptive analysis, the positive correlation between SES and child health can be seen: children in household with higher income and more educated parents tend to be healthier in general. The results from the regression analysis indicate that the child's health status does improve as family SES position increases with household income having a large and positive effect on child health. However, after adding in the mean household income into the regression, the current household income is no longer statistically significant and the coefficient of mean household income shows a positive impact of long-term income on child health. The same pattern is found for parental education. Positive state dependence of child health is observed from the results in all dynamic models. The coefficients of health lags indicate persistence in health from childhood to adolescence. Using Wooldridge's random effects specification, unobserved heterogeneity explained approximately $31 \%$ of the latent error variance. Lastly, subgroup analysis shows that the low health state is more persistent in neighborhoods with lower income and in neighborhoods with less educated people than in neighborhoods with more educated people. Nonetheless, there is no discernable pattern across neighborhoods with different living arrangements and across neighborhood with different proportions of lone-parents families. It indicates that controlling for family level characteristics it is rather the "affluence" status of a neighbourhood than "socioeconomic disadvantage" of a neighborhood that contributes to explaining persistence in health. Accordingly, the predictions from the subgroup analysis indicates that children living in poorer neighborhoods and in neighborhoods with lower education level tend to experience poor health status for longer after a transition to it, while children tend to experience multiple health drops living in poorer neighborhoods, in neighborhoods with less educated people, in neighborhoods with more families headed by lone-parents and in neighborhoods with more families living in rental accommodations. 
Table 6. Dynamic ordered probit models estimates

\begin{tabular}{|c|c|c|c|c|}
\hline \multirow[b]{2}{*}{ hlthc(t-1)poor } & \multicolumn{2}{|c|}{$\begin{array}{c}(1) \\
\text { Pooled model, without correlated } \\
\text { effects specifications }\end{array}$} & \multicolumn{2}{|c|}{$\begin{array}{l}(2) \\
\text { Random effects, with correlated } \\
\text { effects specifications }\end{array}$} \\
\hline & -1.9465 & $(0.2692)$ & -0.9075 & $(0.2619)$ \\
\hline hlthc(t-1)fair & -1.1673 & $(0.0940)$ & -0.4434 & $(0.0913)$ \\
\hline hlthc(t-1)good & -0.5472 & $(0.0328)$ & -0.2359 & $(0.0357)$ \\
\hline hlthc(t-1)excellent & 0.7522 & $(0.0219)$ & 0.2958 & $(0.0266)$ \\
\hline child age & -0.0056 & $(0.0028)$ & -0.0033 & $(0.0039)$ \\
\hline child gender & -0.0414 & $(0.0195)$ & -0.0492 & $(0.0291)$ \\
\hline family size & 0.0293 & $(0.0100)$ & -0.0353 & $(0.0270)$ \\
\hline mbirthage & -0.0075 & $(0.0023)$ & -0.0160 & $(0.0035)$ \\
\hline $\ln$ (hh income) & 0.1716 & $(0.0209)$ & 0.0242 & $(0.0353)$ \\
\hline mother school2 & 0.1345 & $(0.0376)$ & 0.1029 & $(0.0550)$ \\
\hline mother school3 & 0.1699 & $(0.0392)$ & 0.0889 & $(0.0655)$ \\
\hline mother school4 & 0.2257 & $(0.0372)$ & 0.1226 & $(0.0724)$ \\
\hline father school2 & 0.0684 & $(0.0322)$ & 0.0146 & $(0.0457)$ \\
\hline father school3 & 0.0578 & $(0.0343)$ & -0.0446 & $(0.0568)$ \\
\hline father school4 & 0.0709 & $(0.0311)$ & -0.0824 & $(0.0634)$ \\
\hline PMK not mother & -0.5401 & $(0.3190)$ & -0.4900 & $(0.7222)$ \\
\hline mother school2*PMKnm & -0.2607 & $(0.1695)$ & -0.3222 & $(0.1838)$ \\
\hline mother school3*PMKnm & -0.1652 & $(0.1578)$ & -0.1578 & $(0.1889)$ \\
\hline mother school4*PMKnm & -0.1663 & $(0.1526)$ & -0.1932 & $(0.1793)$ \\
\hline PMK female & -0.8000 & $(0.2866)$ & -0.8624 & $(0.7041)$ \\
\hline living w/ two parents & -0.3429 & $(0.4072)$ & -0.6116 & $(0.5525)$ \\
\hline hlthc(1)poor & & & -1.3046 & $(0.3357)$ \\
\hline hlthc(1)fair & & & -0.6799 & $(0.1385)$ \\
\hline hlthc(1)good & & & -0.2174 & $(0.0555)$ \\
\hline hlthc(1)excellent & & & 0.5027 & $(0.0359)$ \\
\hline mln(hh income) & & & 0.3097 & $(0.0534)$ \\
\hline magec & & & 0.0010 & $(0.0096)$ \\
\hline mfsize & & & 0.0963 & $(0.0324)$ \\
\hline mschoolm & & & 0.0640 & $(0.0293)$ \\
\hline mschoolf & & & 0.0600 & $(0.0262)$ \\
\hline mpmknm & & & 0.7525 & $(1.5485)$ \\
\hline mpmkfe & & & 0.8843 & (1.4947) \\
\hline mtwopar & & & 1.3220 & $(2.0068)$ \\
\hline msmxmpm & & & -0.0177 & $(0.1244)$ \\
\hline cut1 & -2.5018 & $(0.5447)$ & 0.6683 & $(2.4542)$ \\
\hline cut2 & -1.5623 & $(0.5375)$ & 1.7631 & $(2.4532)$ \\
\hline cut3 & -0.3537 & $(0.5354)$ & 3.1761 & $(2.4530)$ \\
\hline cut4 & 0.8378 & $(0.5354)$ & 4.5725 & $(2.4532)$ \\
\hline ICC & & & 0.3065 & $(0.0135)$ \\
\hline Log likelihood & \multicolumn{2}{|c|}{-16164.9} & \multicolumn{2}{|c|}{-15749.8} \\
\hline
\end{tabular}

1. Standard errors are reported in parentheses. These are robust to cluster effects for the pooled specification.

2. ICC is the intra-class correlation coefficient, $\left(\sigma_{u}^{2} /\left(1+\sigma_{u}^{2}\right)\right)$ 
Table 7. Average partial effects on probability of reporting excellent health

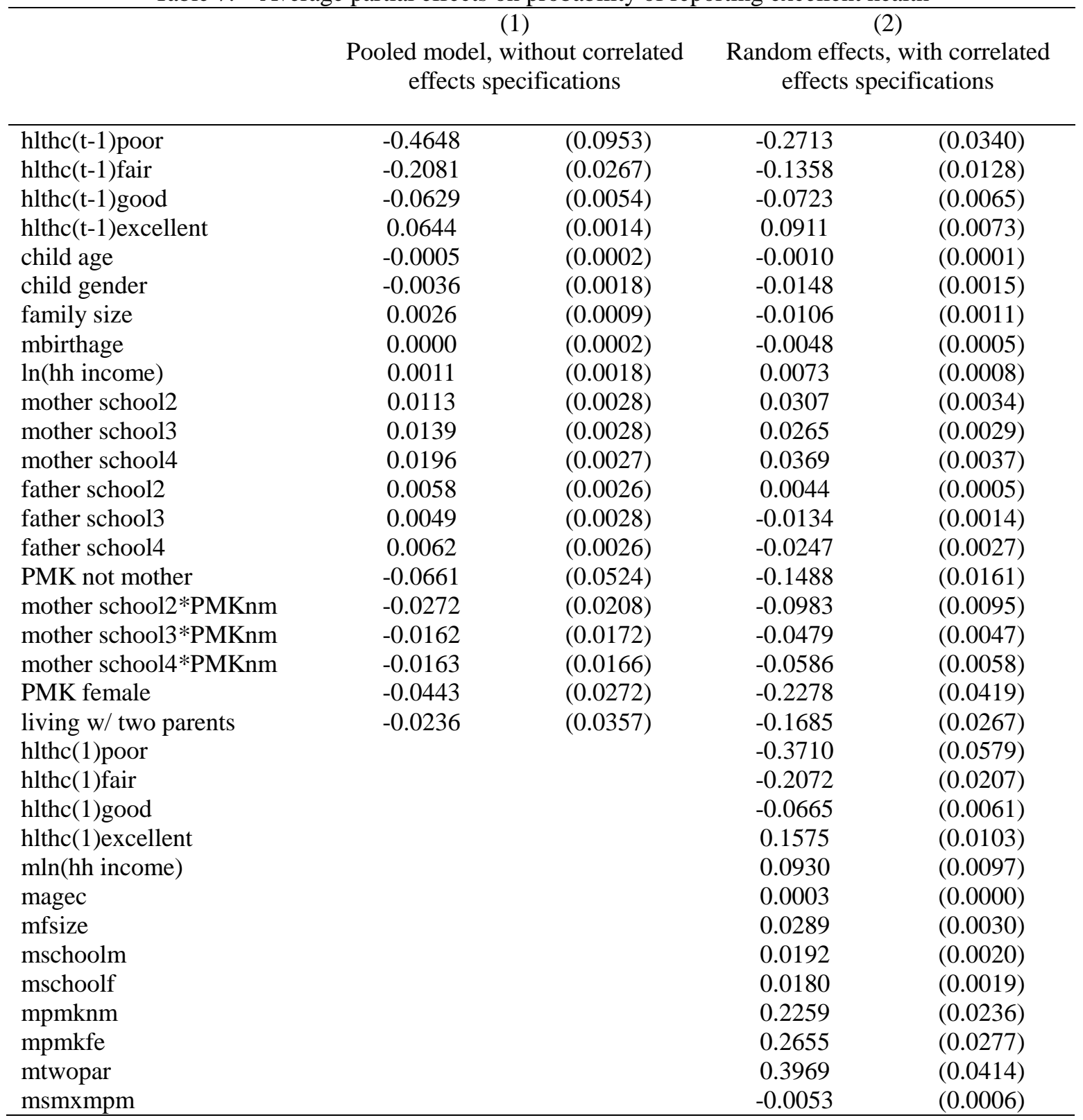

1. Standard errors are reported in parentheses.

Table 8. Transition matrix for empirical model, balanced whole sample

\begin{tabular}{cccccc}
\hline & & $\begin{array}{c}\text { Fair/Poor } \\
\mathrm{t}\end{array}$ & $\begin{array}{c}\text { Good } \\
\mathrm{t}\end{array}$ & $\begin{array}{c}\text { Very Good } \\
\mathrm{t}\end{array}$ & $\begin{array}{c}\text { Excellent } \\
\mathrm{t}\end{array}$ \\
\hline Fair/Poor & $\mathrm{t}-1$ & 0.089 & 0.289 & 0.391 & 0.231 \\
Good & $\mathrm{t}-1$ & 0.030 & 0.191 & 0.409 & 0.369 \\
Very Good & $\mathrm{t}-1$ & 0.013 & 0.121 & 0.368 & 0.498 \\
Excellent & $\mathrm{t}-1$ & 0.004 & 0.058 & 0.274 & 0.664 \\
\hline
\end{tabular}


Table 9. Average Partial effects for the probability of reporting excellent health by neighbourhood status, random effects model

\begin{tabular}{|c|c|c|c|c|c|c|c|c|}
\hline & \multicolumn{8}{|c|}{ (1) By quartiles of mean household income of neighbourhood } \\
\hline & \multicolumn{2}{|c|}{ Lowest income } & \multicolumn{2}{|c|}{ Second lowest income } & \multicolumn{2}{|c|}{ Middle income } & \multicolumn{2}{|c|}{ Highest income } \\
\hline hlthc(t-1)poor/fair & -0.1064 & $(0.0117)$ & -0.0836 & $(0.0091)$ & -0.2509 & $(0.0279)$ & -0.0918 & $(0.0096)$ \\
\hline hlthc(t-1)good & -0.0388 & $(0.0040)$ & -0.0264 & $(0.0029)$ & -0.1228 & $(0.0123)$ & -0.0867 & $(0.0090)$ \\
\hline hlthc(t-1)excellent & 0.1006 & $(0.0085)$ & 0.1087 & $(0.0092)$ & 0.0633 & $(0.0062)$ & 0.0789 & $(0.0086)$ \\
\hline child age & 0.0009 & $(0.0001)$ & -0.0051 & $(0.0006)$ & 0.0010 & $(0.0001)$ & 0.0008 & $(0.0001)$ \\
\hline child gender & 0.0061 & $(0.0007)$ & -0.0056 & $(0.0006)$ & -0.0295 & $(0.0032)$ & -0.0155 & $(0.0021)$ \\
\hline family size & -0.0203 & $(0.0022)$ & 0.0012 & $(0.0001)$ & -0.0043 & $(0.0005)$ & -0.0159 & $(0.0022)$ \\
\hline mbirthage & -0.0061 & $(0.0007)$ & -0.0043 & $(0.0005)$ & -0.0013 & $(0.0001)$ & -0.0061 & $(0.0008)$ \\
\hline $\ln ($ hh income) & 0.0166 & $(0.0018)$ & 0.0191 & $(0.0022)$ & 0.0113 & $(0.0013)$ & -0.0242 & $(0.0033)$ \\
\hline mother school2 & 0.0140 & $(0.0016)$ & -0.0071 & $(0.0008)$ & 0.0861 & $(0.0109)$ & 0.0237 & $(0.0034)$ \\
\hline mother school3 & -0.0391 & $(0.0043)$ & -0.0346 & (0.0038) & 0.1522 & $(0.0213)$ & 0.0078 & $(0.0011)$ \\
\hline mother school4 & -0.0068 & $(0.0008)$ & 0.0190 & $(0.0021)$ & 0.1445 & $(0.0187)$ & -0.0048 & $(0.0007)$ \\
\hline father school2 & 0.0329 & $(0.0037)$ & -0.0539 & $(0.0060)$ & 0.0316 & $(0.0036)$ & -0.0247 & $(0.0032)$ \\
\hline father school3 & 0.0170 & $(0.0019)$ & -0.0778 & $(0.0089)$ & 0.0003 & $(0.0000)$ & -0.0129 & $(0.0017)$ \\
\hline father school4 & -0.0098 & (0.0011) & -0.0982 & (0.0133) & -0.0170 & (0.0019) & 0.0044 & $(0.0006)$ \\
\hline PMK not mother & 0.0598 & $(0.0070)$ & 0.1547 & $(0.0231)$ & 0.0762 & $(0.0092)$ & 0.2595 & $(0.0732)$ \\
\hline schoolm2*PMKnm & 0.0331 & $(0.0038)$ & -0.1148 & $(0.0133)$ & -0.0907 & $(0.0097)$ & -0.3117 & $(0.0316)$ \\
\hline schoolm3*PMKnm & 0.1516 & $(0.0215)$ & -0.2117 & $(0.0290)$ & -0.0754 & $(0.0082)$ & -0.2095 & $(0.0201)$ \\
\hline schoolm4*PMKnm & -0.0575 & $(0.0063)$ & -0.1419 & (0.0175) & -0.0186 & $(0.0020)$ & -0.2628 & $(0.0292)$ \\
\hline hlthc(1)poor/fair & -0.1414 & $(0.0161)$ & -0.2056 & $(0.0248)$ & -0.3449 & $(0.0432)$ & -0.0906 & $(0.0095)$ \\
\hline hlthc(1)good & -0.0819 & $(0.0081)$ & -0.1015 & $(0.0104)$ & -0.0220 & $(0.0024)$ & -0.0356 & $(0.0043)$ \\
\hline hlthc(1)excellent & 0.1687 & $(0.0115)$ & 0.1410 & $(0.0108)$ & 0.1514 & $(0.0123)$ & 0.1904 & $(0.0144)$ \\
\hline mln(hh income) & 0.0307 & $(0.0034)$ & 0.1203 & $(0.0137)$ & 0.0754 & $(0.0084)$ & 0.1483 & $(0.0202)$ \\
\hline magec & 0.0061 & $(0.0007)$ & 0.0094 & $(0.0011)$ & -0.0047 & $(0.0005)$ & -0.0032 & $(0.0004)$ \\
\hline mfsize & 0.0475 & $(0.0052)$ & 0.0068 & $(0.0008)$ & 0.0219 & $(0.0024)$ & 0.0337 & $(0.0046)$ \\
\hline mschoolm & 0.0462 & $(0.0051)$ & 0.0178 & $(0.0020)$ & -0.0344 & $(0.0038)$ & 0.0228 & $(0.0031)$ \\
\hline mschoolf & 0.0283 & $(0.0031)$ & 0.0405 & $(0.0046)$ & 0.0173 & $(0.0019)$ & -0.0178 & $(0.0024)$ \\
\hline mpmknm & -0.2590 & $(0.0286)$ & -0.2574 & $(0.0292)$ & -0.0299 & $(0.0033)$ & 0.4152 & $(0.0564)$ \\
\hline msmxmpm & 0.0198 & $(0.0022)$ & 0.0413 & $(0.0047)$ & 0.0139 & $(0.0015)$ & -0.1483 & $0.0202)$ \\
\hline \multicolumn{9}{|c|}{ (2) By quartiles of proportion of population with university degree in neighbourhood } \\
\hline & \multicolumn{2}{|c|}{ Lowest \% w/ degree } & \multicolumn{2}{|c|}{ Second lowest \% } & \multicolumn{2}{|c|}{ Second highest \% } & \multicolumn{2}{|c|}{ Highest \% w/ degree } \\
\hline hlthc(t-1)poor/fair & -0.1539 & $(0.0147)$ & -0.0384 & $(0.0041)$ & -0.2889 & $(0.0374)$ & -0.1145 & $(0.0134)$ \\
\hline hlthc(t-1)good & -0.0709 & $(0.0062)$ & -0.0265 & $(0.0028)$ & -0.0898 & $(0.0094)$ & -0.0856 & $(0.0100)$ \\
\hline hlthc(t-1)excellent & 0.0789 & $(0.0062)$ & 0.0953 & $(0.0084)$ & 0.0782 & $(0.0078)$ & 0.1097 & $(0.0117)$ \\
\hline child age & -0.0005 & $(0.0000)$ & -0.0077 & $(0.0008)$ & 0.0020 & $(0.0002)$ & 0.0032 & $(0.0005)$ \\
\hline child gender & 0.0136 & $(0.0013)$ & 0.0042 & $(0.0005)$ & -0.0416 & $(0.0050)$ & -0.0192 & $(0.0027)$ \\
\hline family size & -0.0160 & $(0.0016)$ & -0.0031 & $(0.0003)$ & -0.0227 & $(0.0028)$ & 0.0036 & $(0.0005)$ \\
\hline mbirthage & -0.0044 & $(0.0004)$ & -0.0056 & $(0.0006)$ & -0.0005 & $(0.0001)$ & -0.0090 & $(0.0013)$ \\
\hline $\ln ($ hh income $)$ & -0.0166 & $(0.0017)$ & 0.0512 & $(0.0056)$ & 0.0041 & $(0.0005)$ & -0.0161 & $(0.0023)$ \\
\hline mother school2 & -0.0010 & $(0.0001)$ & 0.0379 & $(0.0043)$ & 0.0304 & $(0.0039)$ & 0.0123 & $(0.0018)$ \\
\hline mother school3 & 0.0106 & $(0.0011)$ & 0.0151 & $(0.0017)$ & 0.0471 & $(0.0061)$ & -0.0192 & $(0.0027)$ \\
\hline mother school4 & -0.0040 & $(0.0004)$ & 0.0983 & $(0.0093)$ & 0.0331 & $(0.0040)$ & -0.0068 & $(0.0010)$ \\
\hline father school2 & 0.0193 & $(0.0019)$ & 0.0072 & $(0.0008)$ & -0.0420 & $(0.0049)$ & 0.0535 & $(0.0085)$ \\
\hline father school3 & 0.0239 & $(0.0024)$ & -0.0224 & $(0.0024)$ & -0.0821 & $(0.0098)$ & 0.0349 & $(0.0053)$ \\
\hline father school4 & -0.0064 & $(0.0006)$ & -0.0247 & $(0.0028)$ & -0.0978 & $(0.0140)$ & 0.0187 & $(0.0026)$ \\
\hline PMK not mother & 0.1215 & $(0.0159)$ & 0.0459 & $(0.0052)$ & 0.0511 & $(0.0067)$ & 0.2928 & $(0.0879)$ \\
\hline schoolm2*PMKnm & -0.0160 & $(0.0016)$ & -0.0846 & $(0.0091)$ & -0.0158 & (0.0019) & -0.3389 & $(0.0506)$ \\
\hline schoolm3*PMKnm & -0.0626 & $(0.0060)$ & 0.0918 & $(0.0112)$ & -0.0633 & $(0.0072)$ & -0.2403 & $(0.0308)$ \\
\hline schoolm4*PMKnm & -0.1264 & $(0.0128)$ & 0.0165 & $(0.0018)$ & 0.0104 & $(0.0013)$ & -0.3299 & $(0.0507)$ \\
\hline hlthc(1)poor/fair & -0.1861 & $(0.0185)$ & -0.2771 & $(0.0338)$ & -0.1975 & $(0.0227)$ & -0.2677 & $(0.0314)$ \\
\hline hlthc(1)good & -0.0434 & $(0.0040)$ & -0.1260 & $(0.0125)$ & -0.0245 & $(0.0029)$ & -0.0690 & $(0.0084)$ \\
\hline hlthc(1)excellent & 0.1890 & $(0.0101)$ & 0.1079 & $(0.0091)$ & 0.1726 & $(0.0137)$ & 0.1774 & $(0.0158)$ \\
\hline mln(hh income) & 0.0572 & $(0.0057)$ & 0.0564 & $(0.0062)$ & 0.1139 & (0.0139) & 0.1671 & $(0.0239)$ \\
\hline magec & 0.0101 & $(0.0010)$ & 0.0093 & $(0.0010)$ & -0.0004 & $(0.0000)$ & -0.0106 & $(0.0015)$ \\
\hline mfsize & 0.0257 & $(0.0026)$ & 0.0236 & $(0.0026)$ & 0.0412 & $(0.0050)$ & 0.0210 & $(0.0030)$ \\
\hline mschoolm & 0.0446 & $(0.0044)$ & -0.0117 & $(0.0013)$ & 0.0102 & $(0.0012)$ & 0.0041 & $(0.0006)$ \\
\hline mschoolf & 0.0080 & $(0.0008)$ & 0.0261 & $(0.0029)$ & 0.0464 & $(0.0057)$ & 0.0064 & $(0.0009)$ \\
\hline mpmknm & -0.2377 & $(0.0236)$ & -0.4772 & $(0.0521)$ & 0.4389 & $(0.0535)$ & 0.1511 & $(0.0216)$ \\
\hline msmxmpm & 0.0152 & $(0.0015)$ & 0.1550 & $(0.0169)$ & -0.1252 & $(0.0153)$ & -0.0841 & $(0.0120)$ \\
\hline
\end{tabular}




\begin{tabular}{|c|c|c|c|c|c|c|c|c|}
\hline & \multicolumn{8}{|c|}{ (3) By quartiles of proportion of families headed by lone-parents in neighborhood } \\
\hline & \multicolumn{2}{|c|}{ Highest \% } & \multicolumn{2}{|c|}{ Second highest \% } & \multicolumn{2}{|c|}{ Second lowest \% } & \multicolumn{2}{|c|}{ Lowest \% } \\
\hline hlthc(t-1)poor/fair & -0.1890 & $(0.0249)$ & -0.0515 & $(0.0043)$ & -0.2195 & $(0.0251)$ & -0.1090 & $(0.0112)$ \\
\hline hlthc(t-1)good & -0.0656 & $(0.0070)$ & -0.0475 & $(0.0039)$ & -0.0937 & $(0.0115)$ & -0.0607 & $(0.0064)$ \\
\hline hlthc(t-1)excellent & 0.1115 & $(0.0098)$ & 0.0616 & $(0.0050)$ & 0.0579 & $(0.0075)$ & 0.1256 & $(0.0104)$ \\
\hline child age & 0.0005 & $(0.0001)$ & -0.0019 & $(0.0002)$ & -0.0031 & $(0.0005)$ & 0.0006 & $(0.0001)$ \\
\hline child gender & -0.0268 & $(0.0030)$ & 0.0228 & $(0.0022)$ & -0.0329 & $(0.0048)$ & 0.0067 & $(0.0008)$ \\
\hline family size & -0.0022 & $(0.0002)$ & -0.0144 & $(0.0014)$ & -0.0163 & $(0.0024)$ & -0.0031 & $(0.0004)$ \\
\hline mbirthage & -0.0052 & $(0.0006)$ & -0.0020 & $(0.0002)$ & -0.0074 & $(0.0011)$ & -0.0040 & $(0.0005)$ \\
\hline $\ln$ (hh income) & -0.0030 & $(0.0003)$ & 0.0329 & $(0.0031)$ & 0.0089 & $(0.0013)$ & -0.0066 & $(0.0008)$ \\
\hline mother school2 & 0.0470 & $(0.0053)$ & 0.0171 & $(0.0017)$ & 0.0376 & $(0.0060)$ & 0.0087 & $(0.0011)$ \\
\hline mother school3 & 0.0347 & $(0.0039)$ & 0.0232 & $(0.0023)$ & 0.0345 & $(0.0053)$ & -0.0104 & $(0.0012)$ \\
\hline mother school4 & 0.0872 & $(0.0094)$ & 0.0379 & $(0.0034)$ & 0.0159 & $(0.0024)$ & 0.0056 & $(0.0007)$ \\
\hline father school2 & -0.0025 & $(0.0003)$ & 0.0515 & $(0.0054)$ & 0.0015 & $(0.0002)$ & -0.0384 & $(0.0043)$ \\
\hline father school3 & -0.0233 & $(0.0026)$ & 0.0269 & $(0.0027)$ & -0.0075 & $(0.0011)$ & -0.0482 & $(0.0054)$ \\
\hline father school4 & -0.0465 & $(0.0055)$ & 0.0210 & $(0.0020)$ & -0.0353 & $(0.0054)$ & -0.0487 & $(0.0064)$ \\
\hline PMK not mother & -0.0117 & $(0.0013)$ & 0.1904 & $(0.0313)$ & 0.0598 & $(0.0099)$ & 0.0884 & $(0.0126)$ \\
\hline schoolm2*PMKnm & 0.0461 & $(0.0051)$ & -0.1511 & $(0.0119)$ & -0.0950 & $(0.0121)$ & -0.0014 & $(0.0002)$ \\
\hline schoolm3*PMKnm & 0.1885 & $(0.0245)$ & -0.2384 & $(0.0221)$ & 0.1674 & $(0.0356)$ & -0.0615 & $(0.0067)$ \\
\hline schoolm4*PMKnm & 0.0388 & $(0.0043)$ & -0.1898 & $(0.0181)$ & 0.0268 & $(0.0042)$ & -0.0090 & $(0.0011)$ \\
\hline hlthc(1)poor/fair & -0.2986 & $(0.0471)$ & -0.1764 & $(0.0136)$ & -0.2218 & $(0.0246)$ & -0.1659 & $(0.0168)$ \\
\hline hlthc(1)good & -0.1229 & $(0.0132)$ & 0.0002 & $(0.0000)$ & -0.1028 & $(0.0126)$ & -0.0059 & $(0.0007)$ \\
\hline hlthc(1)excellent & 0.1142 & $(0.0100)$ & 0.1927 & $(0.0095)$ & 0.1590 & (0.0153) & 0.1924 & $(0.0124)$ \\
\hline mln(hh income) & 0.1180 & $(0.0131)$ & 0.0683 & $(0.0065)$ & 0.0978 & $(0.0146)$ & 0.0817 & $(0.0097)$ \\
\hline magec & -0.0032 & $(0.0004)$ & 0.0075 & $(0.0007)$ & 0.0087 & $(0.0013)$ & -0.0040 & $(0.0005)$ \\
\hline mfsize & 0.0290 & $(0.0032)$ & 0.0297 & $(0.0028)$ & 0.0350 & $(0.0052)$ & 0.0166 & $(0.0020)$ \\
\hline mschoolm & -0.0102 & $(0.0011)$ & 0.0105 & $(0.0010)$ & 0.0120 & $(0.0018)$ & 0.0365 & $(0.0043)$ \\
\hline mschoolf & 0.0279 & $(0.0031)$ & -0.0023 & $(0.0002)$ & 0.0287 & $(0.0043)$ & 0.0269 & $(0.0032)$ \\
\hline mpmknm & 0.2313 & $(0.0258)$ & -0.4806 & $(0.0458)$ & -0.1445 & $(0.0215)$ & 0.0098 & $(0.0012)$ \\
\hline \multirow[t]{3}{*}{ msmxmpm } & -0.0993 & $(0.0111)$ & 0.1347 & $(0.0128)$ & 0.0187 & $(0.0028)$ & -0.0246 & $(0.0029)$ \\
\hline & \multicolumn{8}{|c|}{ (4) By quartiles of proportion of families living in rental accommodations in neighborhood } \\
\hline & \multicolumn{2}{|c|}{$\begin{array}{l}\text { Highest \% with rental } \\
\text { accommodations }\end{array}$} & \multicolumn{2}{|c|}{ Second highest \% } & \multicolumn{2}{|c|}{ Second lowest \% } & \multicolumn{2}{|c|}{$\begin{array}{l}\text { Lowest \% with rental } \\
\text { accommodations }\end{array}$} \\
\hline hlthc(t-1)poor/fair & -0.1237 & $(0.0108)$ & -0.1742 & $(0.0186)$ & -0.1389 & $(0.0155)$ & -0.1457 & $(0.0145)$ \\
\hline hlthc(t-1)good & -0.0591 & $(0.0048)$ & -0.1117 & $(0.0106)$ & -0.0315 & $(0.0040)$ & -0.0578 & $(0.0058)$ \\
\hline hlthc(t-1)excellent & 0.0933 & $(0.0065)$ & 0.0905 & $(0.0085)$ & 0.0874 & $(0.0095)$ & 0.0779 & (0.0071) \\
\hline child age & 0.0027 & $(0.0002)$ & -0.0021 & $(0.0003)$ & -0.0060 & $(0.0008)$ & 0.0025 & $(0.0003)$ \\
\hline child gender & -0.0100 & $(0.0009)$ & -0.0007 & $(0.0001)$ & -0.0109 & $(0.0015)$ & -0.0177 & $(0.0020)$ \\
\hline family size & 0.0203 & $(0.0018)$ & -0.0157 & (0.0019) & -0.0370 & $(0.0050)$ & -0.0128 & $(0.0014)$ \\
\hline mbirthage & -0.0045 & $(0.0004)$ & -0.0020 & $(0.0002)$ & -0.0073 & $(0.0010)$ & -0.0058 & $(0.0007)$ \\
\hline $\ln ($ hh income) & -0.0218 & $(0.0020)$ & 0.0221 & $(0.0026)$ & 0.0179 & $(0.0024)$ & 0.0064 & $(0.0007)$ \\
\hline mother school2 & 0.0433 & $(0.0042)$ & 0.0377 & $(0.0048)$ & 0.0310 & $(0.0045)$ & -0.0029 & (0.0003) \\
\hline mother school3 & 0.0480 & $(0.0047)$ & 0.0368 & $(0.0046)$ & 0.0451 & $(0.0066)$ & -0.0407 & $(0.0044)$ \\
\hline mother school4 & 0.1068 & $(0.0090)$ & 0.0318 & $(0.0037)$ & 0.0669 & $(0.0085)$ & -0.0531 & (0.0066) \\
\hline father school2 & 0.0138 & $(0.0013)$ & 0.0032 & $(0.0004)$ & -0.0092 & $(0.0012)$ & -0.0011 & $(0.0001)$ \\
\hline father school3 & 0.0036 & $(0.0003)$ & 0.0026 & $(0.0003)$ & -0.0688 & (0.0089) & -0.0080 & (0.0009) \\
\hline father school4 & -0.0092 & $(0.0008)$ & -0.0166 & $(0.0020)$ & -0.0914 & $(0.0142)$ & -0.0097 & $(0.0011)$ \\
\hline PMK not mother & 0.0918 & $(0.0097)$ & 0.2482 & $(0.0505)$ & -0.0120 & $(0.0016)$ & 0.0556 & (0.0069) \\
\hline schoolm2*PMKnm & -0.0209 & (0.0019) & -0.2648 & $(0.0349)$ & 0.0528 & $(0.0080)$ & -0.0648 & $(0.0067)$ \\
\hline schoolm3*PMKnm & 0.0412 & $(0.0039)$ & -0.3087 & $(0.0451)$ & 0.1894 & (0.0399) & -0.0605 & (0.0063) \\
\hline schoolm4*PMKnm & -0.0514 & $(0.0046)$ & -0.2292 & $(0.0311)$ & 0.0399 & $(0.0059)$ & -0.0022 & $(0.0002)$ \\
\hline hlthc(1)poor/fair & -0.2590 & $(0.0269)$ & -0.2200 & $(0.0249)$ & -0.2328 & $(0.0270)$ & -0.1872 & (0.0183) \\
\hline hlthc(1)good & -0.0840 & $(0.0069)$ & -0.0966 & $(0.0095)$ & -0.0954 & $(0.0108)$ & 0.0237 & $(0.0028)$ \\
\hline hlthc(1)excellent & 0.1248 & $(0.0079)$ & 0.1281 & $(0.0107)$ & 0.1762 & $(0.0146)$ & 0.2258 & $(0.0127)$ \\
\hline mln(hh income) & 0.1325 & $(0.0120)$ & 0.1160 & $(0.0139)$ & 0.0916 & $(0.0124)$ & 0.0502 & $(0.0056)$ \\
\hline magec & -0.0102 & $(0.0009)$ & 0.0085 & $(0.0010)$ & 0.0088 & $(0.0012)$ & -0.0015 & $(0.0002)$ \\
\hline mfsize & -0.0086 & $(0.0008)$ & 0.0375 & $(0.0045)$ & 0.0704 & $(0.0095)$ & 0.0179 & $(0.0020)$ \\
\hline mschoolm & -0.0315 & $(0.0029)$ & 0.0200 & $(0.0024)$ & 0.0026 & $(0.0003)$ & 0.0598 & (0.0067) \\
\hline mschoolf & 0.0243 & $(0.0022)$ & 0.0027 & $(0.0003)$ & 0.0500 & $(0.0068)$ & 0.0188 & $(0.0021)$ \\
\hline mpmknm & -0.2331 & $(0.0211)$ & 0.0347 & $(0.0042)$ & -0.0227 & $(0.0031)$ & 0.1179 & $(0.0132)$ \\
\hline msmxmpm & 0.0335 & $(0.0030)$ & 0.0066 & $(0.0008)$ & -0.0700 & $(0.0095)$ & -0.0339 & (0.0038) \\
\hline
\end{tabular}


Table 10. Transition matrices by neighbourhood status for empirical model

By quartiles of mean household income of neighbourhood

\begin{tabular}{|c|c|c|c|c|c|c|c|c|c|c|c|c|c|c|c|}
\hline \multicolumn{4}{|c|}{ Lowest income } & \multicolumn{4}{|c|}{ Second lowest income } & \multicolumn{4}{|c|}{ Middle income } & \multicolumn{4}{|c|}{ Highest income } \\
\hline & $\begin{array}{c}< \\
\text { Good }\end{array}$ & $\begin{array}{c}\text { Very } \\
\text { Good }\end{array}$ & Ex & & $\begin{array}{c}< \\
\text { Good }\end{array}$ & $\begin{array}{l}\text { Very } \\
\text { Good }\end{array}$ & Ex & & $\begin{array}{c}< \\
\text { Good }\end{array}$ & $\begin{array}{l}\text { Very } \\
\text { Good }\end{array}$ & Ex & & $\begin{array}{c}< \\
\text { Good }\end{array}$ & $\begin{array}{l}\text { Very } \\
\text { Good }\end{array}$ & Ex \\
\hline$<$ Good & 0.251 & 0.409 & 0.339 & $<$ Good & 0.230 & 0.425 & 0.345 & $<$ Good & 0.245 & 0.399 & 0.356 & $<$ Good & 0.196 & 0.400 & 0.404 \\
\hline Very Good & 0.157 & 0.383 & 0.460 & Very Good & 0.151 & 0.400 & 0.449 & Very Good & 0.124 & 0.350 & 0.527 & Very Good & 0.108 & 0.339 & 0.553 \\
\hline Excellent & 0.073 & 0.291 & 0.637 & Excellent & 0.065 & 0.294 & 0.641 & Excellent & 0.065 & 0.276 & 0.659 & Excellent & 0.047 & 0.238 & 0.715 \\
\hline
\end{tabular}

By quartiles of proportion of population with university degree in neighbourhood

\begin{tabular}{|c|c|c|c|c|c|c|c|c|c|c|c|c|c|c|c|}
\hline \multicolumn{4}{|c|}{ Lowest \% with college degree } & \multicolumn{4}{|c|}{ Second lowest \% } & \multicolumn{4}{|c|}{ Second highest \% } & \multicolumn{4}{|c|}{ Highest \% with college degree } \\
\hline & $\begin{array}{c}< \\
\text { Good }\end{array}$ & $\begin{array}{l}\text { Very } \\
\text { Good }\end{array}$ & Ex & & $\begin{array}{c}< \\
\text { Good }\end{array}$ & $\begin{array}{l}\text { Very } \\
\text { Good }\end{array}$ & Ex & & $\begin{array}{c}< \\
\text { Good }\end{array}$ & $\begin{array}{l}\text { Very } \\
\text { Good }\end{array}$ & Ex & & $\begin{array}{c}< \\
\text { Good }\end{array}$ & $\begin{array}{l}\text { Very } \\
\text { Good }\end{array}$ & Ex \\
\hline$<$ Good & 0.243 & 0.415 & 0.342 & $<$ Good & 0.241 & 0.383 & 0.376 & $<$ Good & 0.242 & 0.416 & 0.342 & $<$ Good & 0.214 & 0.427 & 0.359 \\
\hline Very Good & 0.141 & 0.374 & 0.484 & Very Good & 0.160 & 0.361 & 0.479 & Very Good & 0.129 & 0.372 & 0.499 & Very Good & 0.117 & 0.377 & 0.506 \\
\hline Excellent & 0.067 & 0.284 & 0.649 & Excellent & 0.082 & 0.284 & 0.634 & Excellent & 0.057 & 0.274 & 0.669 & Excellent & 0.042 & 0.252 & 0.706 \\
\hline
\end{tabular}

By quartiles of proportion of families headed by lone-parents in neighborhood

\begin{tabular}{|c|c|c|c|c|c|c|c|c|c|c|c|c|c|c|c|}
\hline \multicolumn{4}{|c|}{ Highest \% with lone-parents } & \multicolumn{4}{|c|}{ Second highest \% } & \multicolumn{4}{|c|}{ Second lowest \% } & \multicolumn{4}{|c|}{ Lowest \% with lone-parents } \\
\hline & $\begin{array}{c}< \\
\text { Good }\end{array}$ & $\begin{array}{l}\text { Very } \\
\text { Good }\end{array}$ & Ex & & $\begin{array}{c}< \\
\text { Good }\end{array}$ & $\begin{array}{l}\text { Very } \\
\text { Good }\end{array}$ & Ex & & $\begin{array}{c}< \\
\text { Good }\end{array}$ & $\begin{array}{l}\text { Very } \\
\text { Good }\end{array}$ & Ex & & $\begin{array}{c}< \\
\text { Good }\end{array}$ & $\begin{array}{l}\text { Very } \\
\text { Good }\end{array}$ & Ex \\
\hline$<$ Good & 0.280 & 0.409 & 0.311 & $<$ Good & 0.199 & 0.379 & 0.422 & $<$ Good & 0.240 & 0.409 & 0.351 & $<$ Good & 0.210 & 0.434 & 0.355 \\
\hline Very Good & 0.154 & 0.389 & 0.457 & Very Good & 0.142 & 0.347 & 0.512 & Very Good & 0.112 & 0.348 & 0.540 & Very Good & 0.137 & 0.397 & 0.466 \\
\hline Excellent & 0.074 & 0.301 & 0.625 & Excellent & 0.073 & 0.271 & 0.655 & Excellent & 0.053 & 0.255 & 0.692 & Excellent & 0.048 & 0.270 & 0.682 \\
\hline
\end{tabular}

By quartiles of proportion of families living in rental accommodations in neighborhood

\begin{tabular}{|c|c|c|c|c|c|c|c|c|c|c|c|c|c|c|c|}
\hline \multicolumn{4}{|c|}{$\begin{array}{l}\text { Highest \% with rental } \\
\text { accommodations }\end{array}$} & \multicolumn{4}{|c|}{ Second highest \% } & \multicolumn{4}{|c|}{ Second lowest \% } & \multicolumn{4}{|c|}{$\begin{array}{c}\text { Lowest \% with rental } \\
\text { accommodations }\end{array}$} \\
\hline & $\begin{array}{c}< \\
\text { Good }\end{array}$ & $\begin{array}{l}\text { Very } \\
\text { Good }\end{array}$ & Ex & & $\begin{array}{c}< \\
\text { Good }\end{array}$ & $\begin{array}{l}\text { Very } \\
\text { Good }\end{array}$ & Ex & & $\begin{array}{c}< \\
\text { Good }\end{array}$ & $\begin{array}{l}\text { Very } \\
\text { Good }\end{array}$ & Ex & & $\begin{array}{c}< \\
\text { Good }\end{array}$ & $\begin{array}{l}\text { Very } \\
\text { Good }\end{array}$ & Ex \\
\hline$<$ Good & 0.237 & 0.391 & 0.372 & $<$ Good & 0.258 & 0.411 & 0.331 & $<$ Good & 0.224 & 0.420 & 0.357 & $<$ Good & 0.211 & 0.410 & 0.379 \\
\hline Very Good & 0.147 & 0.362 & 0.490 & Very Good & 0.131 & 0.364 & 0.505 & Very Good & 0.130 & 0.377 & 0.493 & Very Good & 0.138 & 0.376 & 0.486 \\
\hline Excellent & 0.076 & 0.284 & 0.641 & Excellent & 0.061 & 0.271 & 0.668 & Excellent & 0.056 & 0.269 & 0.675 & Excellent & 0.057 & 0.273 & 0.670 \\
\hline
\end{tabular}




\section{References}

Arellano, M.(2003) 'Discrete choice with panel data'. Investigaciones Economicas ХХУШ (3), 423-458

Boyle, M., Georgiades, K., Racine, Y. and Mustard, C. (2007) 'Neighbourhood and family influences on educational attainment: results from the Ontario Child Health Study follow-up 2001' Child

Development vol. 78, number 1: 168-189

Brooks-Gunn, J., Duncan, G., Klebanov, P.K., and Sealand, N. (1993) 'Do neighbourhoods influence child and adolescent development?’ American Journal of Sociology Vol. 99: 353-395

Buckley, N.J., Denton, F. T., Robb, A.L. and Spencer, B. G. (2004) 'The transition from good to poor health: an econometric study of the old population’ Journal of Health Economics vol. 23: 1013-1034

Canadian Institute for Health Information (CIHI) (2005) 'Improving the health of Young Canadians' Ottawa: Author. <http://www.cihi.ca/youth>

Case, A., Lubotsky, D. and Paxson, C. (2002) 'Economic Status and Health in Childhood: The Origins of the Gradient’ American Economic Review Vol. 92, 5: 1308-1334

Case, A., Fertig, A and Paxson, C. (2005) 'The lasting impact of childhood health and circumstance' Journal of Health Economics 24: 365-389

Contoyannis, P., Jones, A.M., and Rice, N. (2004a) 'Simulation-based inference in dynamic panel ordered probit models: an application to health’ Empirical Economics, vol. 29: 49-77

Contoyannis, P., Jones, A.M., and Rice, N. (2004b) 'The dynamics of health in the British Household Panel Survey’ Journal of Applied Econometrics, vol. 19: 473-503

Currie, J (2000) 'Child health in developed countries' in Joseph P. Newhouse and Anthony J. Culyer, eds., Handbook of health economics, Vol. 17. Amsterdam: North-Holland, pp. 1053-90

Currie, J and Stabile, M. (2003) 'Socio-economic status and child health: Why is the relationship stronger for older children?’ American Economic Review Vol. 93, 5: 1813-1823

Curtis, Lori J.; Dooley, Martin; Lipman, Ellen L. and Feeny, David H. (2001) 'The role of permanent income and family structure in the determination of child health in Canada' Health Economics, Vol. 10 (4): 287-302

Deaton, Angus and Paxson, Christina (1999) 'Mortality, education, income and inequality among American cohorts’ NBER working paper No. 7141

Dooley, Martin and Stewart, Jennifer (2004) 'Family income and child outcomes in Canada' Canadian Journal of Economics, Vol. 37(4): 898-917

Ford, Graeme et al. (1994) 'Patterns of class inequality in health through the life-span: class gradients at 15, 35, and 55 years in the west of Scotland' Social Science and Medicine, 39(8): 1037-50

Garner, C. and Raudenbush, S.W. (1991) 'Neighbourhood effects on educational attainment: A multilevel analysis’ Sociology of Education, Vol.6: 251-262

Hauck, K. and Rice, N. (2004) ‘A longitudinal analysis of mental health mobility in Britain’, Health 
Economics, vol. 13: 981-1001

Heckman, J. (2006) Proceedings of the National Academy of Sciences of the United States of America

Honore, B.E. and Tamer, E. (2006) 'Bounds on parameters in dynamic discrete choice models', Econometrica, vol. 74: 611-629

Jones, A.M., Rice, N. and Contoyannis, P. (2006) 'The dynamics of health', Chapter 2 in The Elgar Companion To Health Economics, Edward Elgar Publishing Limited,

Leventhal, T. and Brooks-Gunn, J. (2000) 'The neighbourhoods they live in: the effects of neighbourhood residence on child and adolescent outcomes' Psychological Bulletin, vol. 126, no. 2: 309-337

Power, C. and Matthews, S. (1997) 'Origins of health inequalities in a national population sample' Lancet, 350(9091): 1584-1589

Wooldridge, J. (2005) 'Simple solutions to the initial conditions problem in dynamic, nonlinear panel data models with unobserved heterogeneity’ Journal of Applied Econometrics vol. 20: 39-54 
Appendix A. Figures

Figure 1. Health status by cycle

$\square$ Excellent $\square$ Very Good $\square$ Good $\square$ Fair/Poor

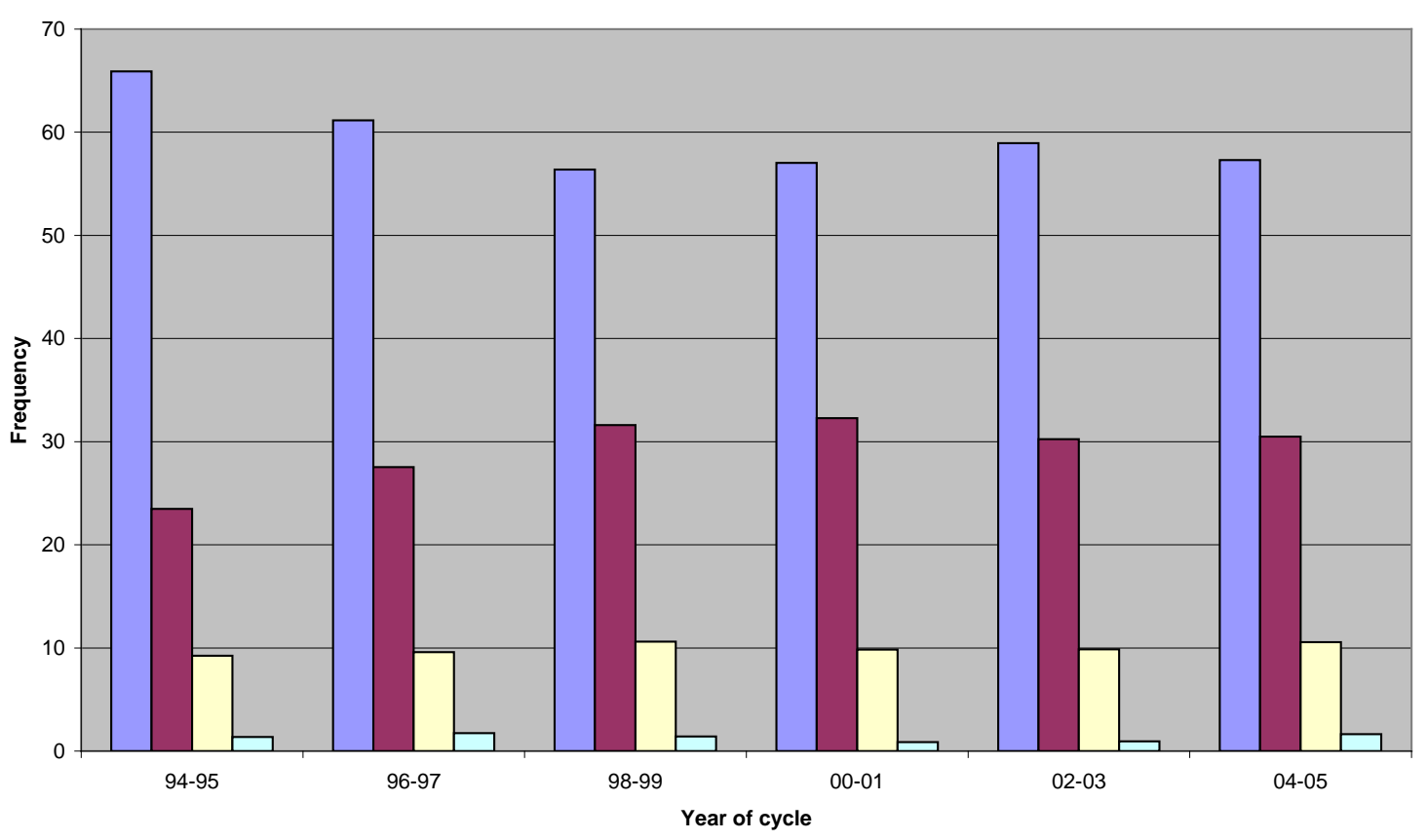

Figure 2. Health status by age group at cycle 1

$\square$ Excellent $\square$ Very Good $\square$ Good $\square$ Fair/Poor

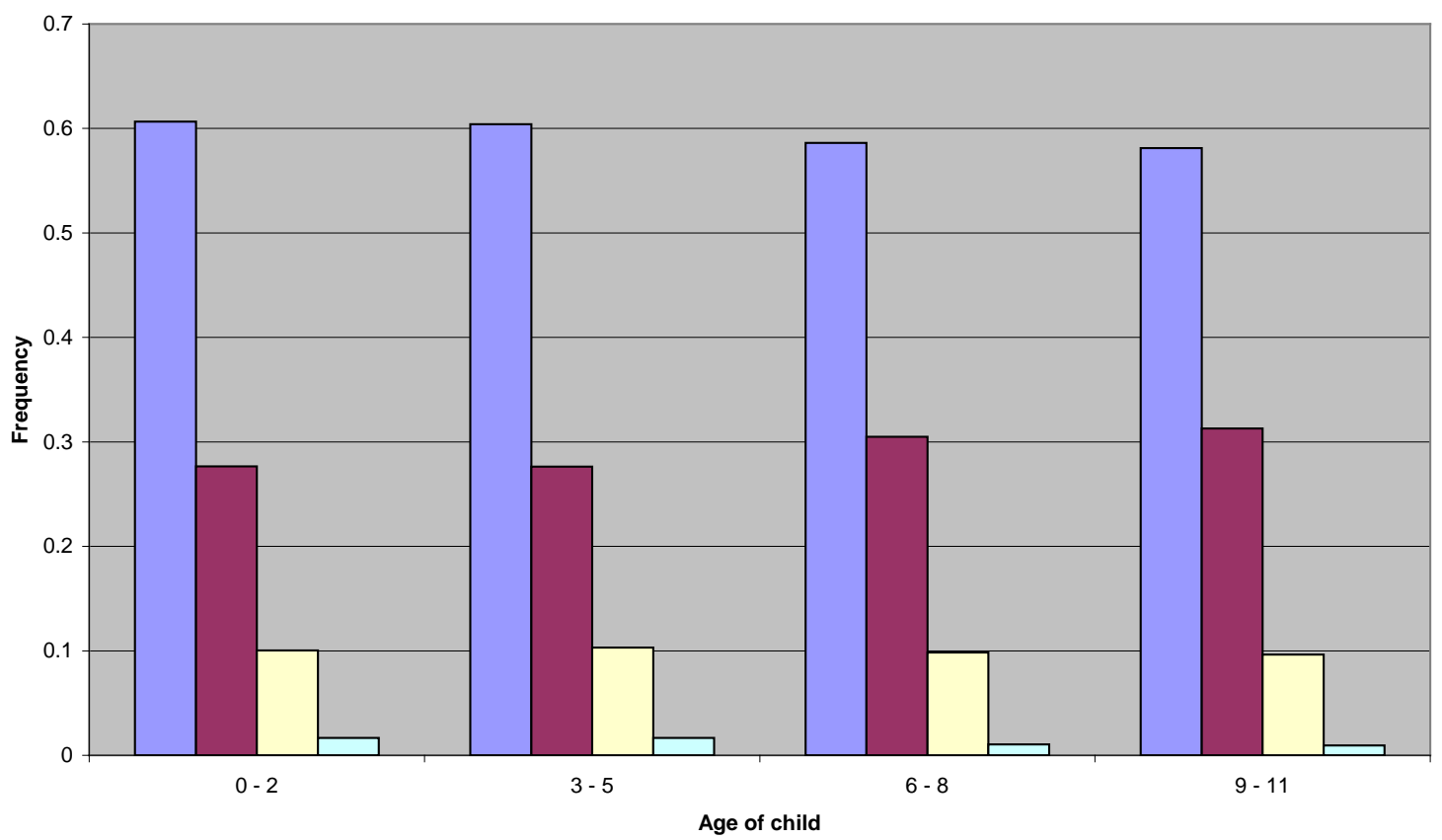


Figure 3. Health status by income class

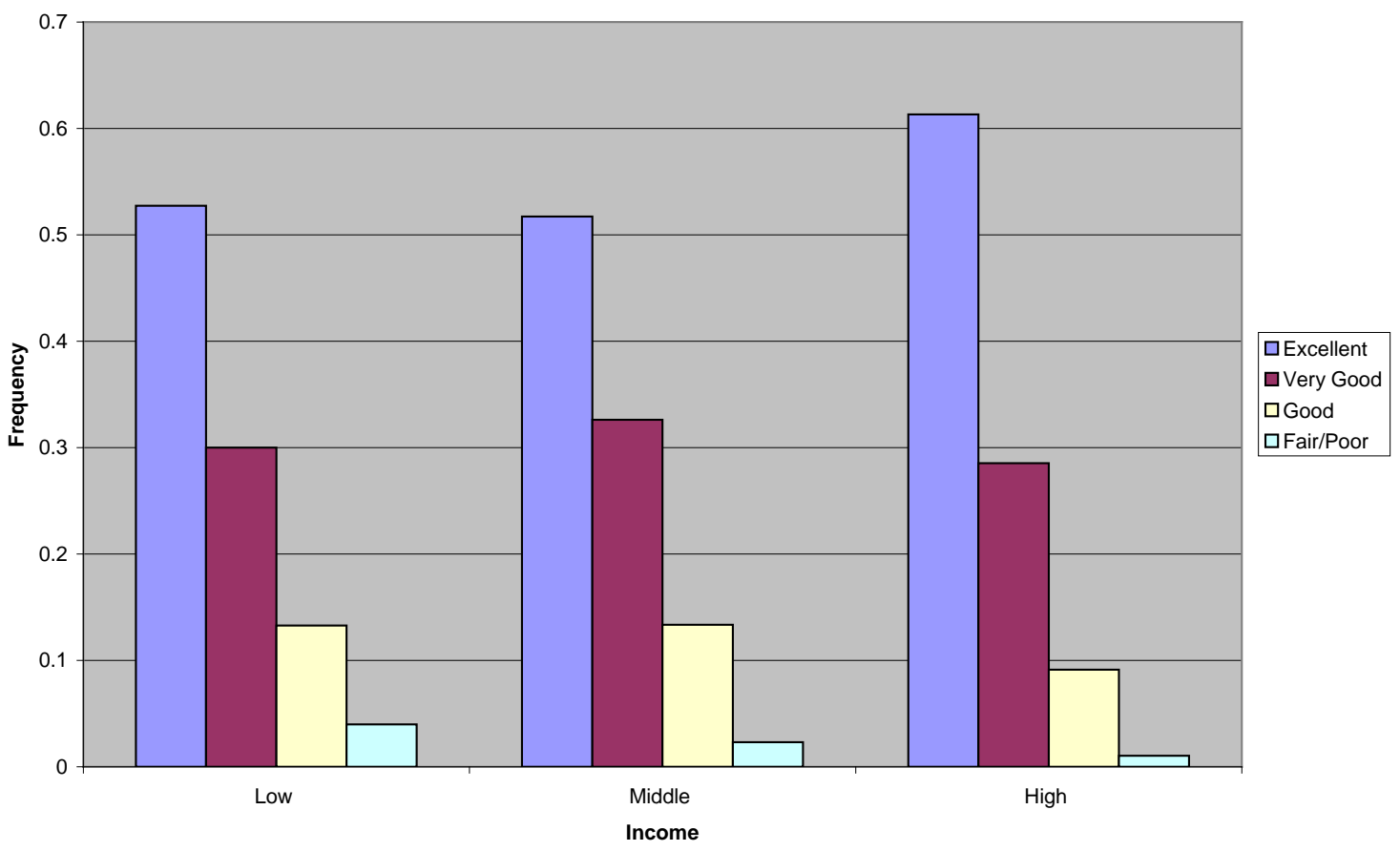

Figure 4. Health status by mother's education

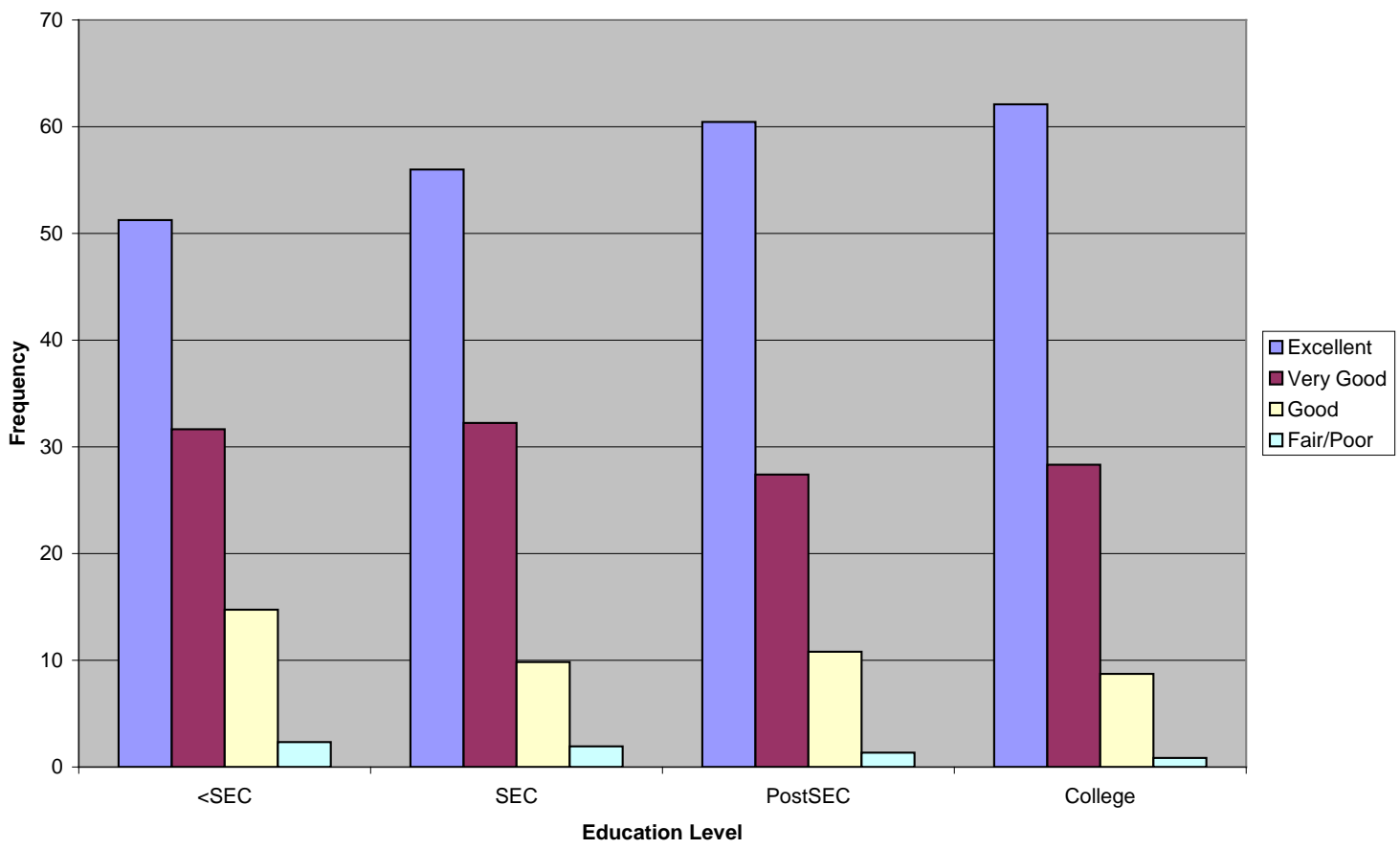


Figure 5. Health status by father's education

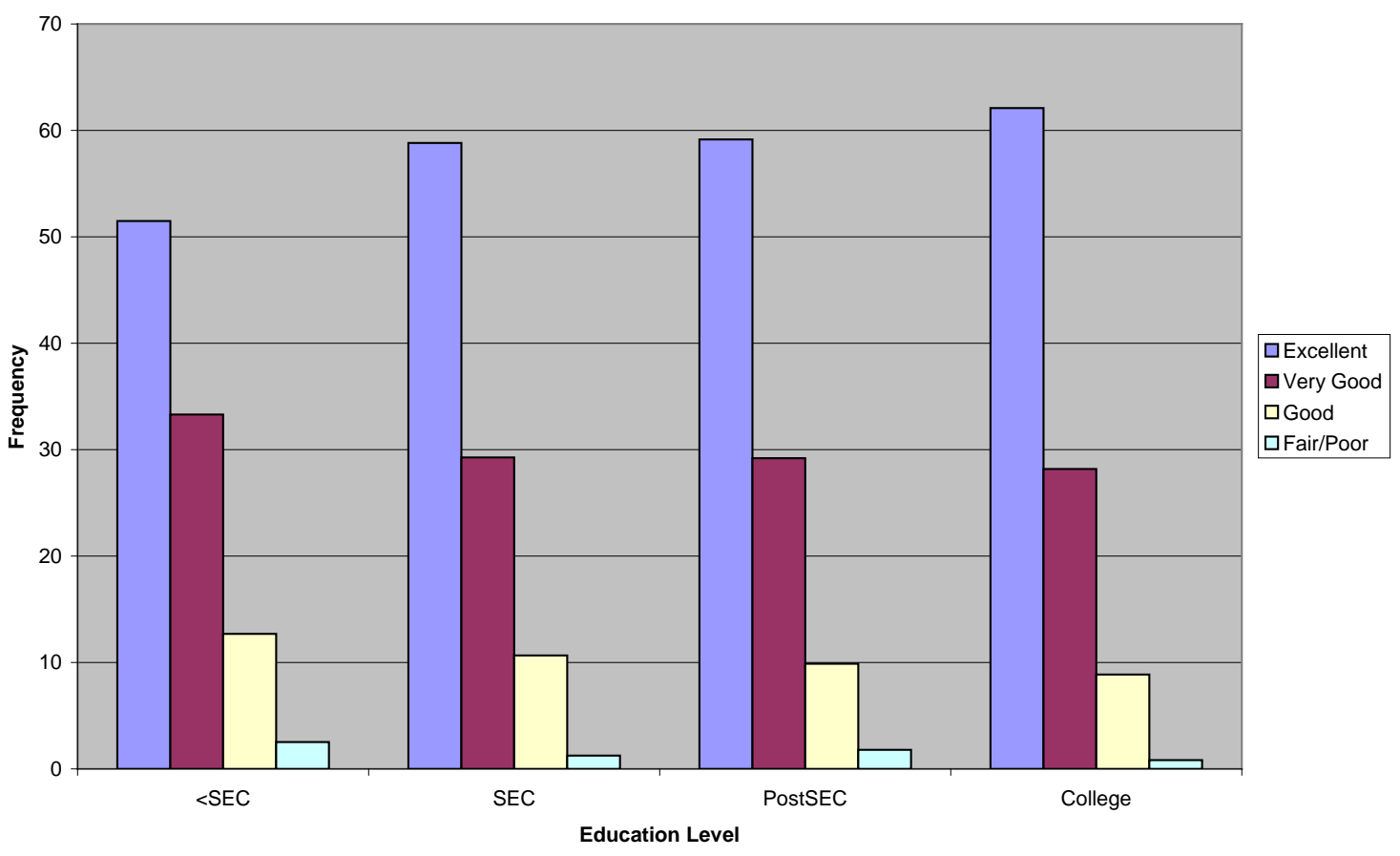

Figure 6. Health Status at cycle 2 by health status at cycle 1

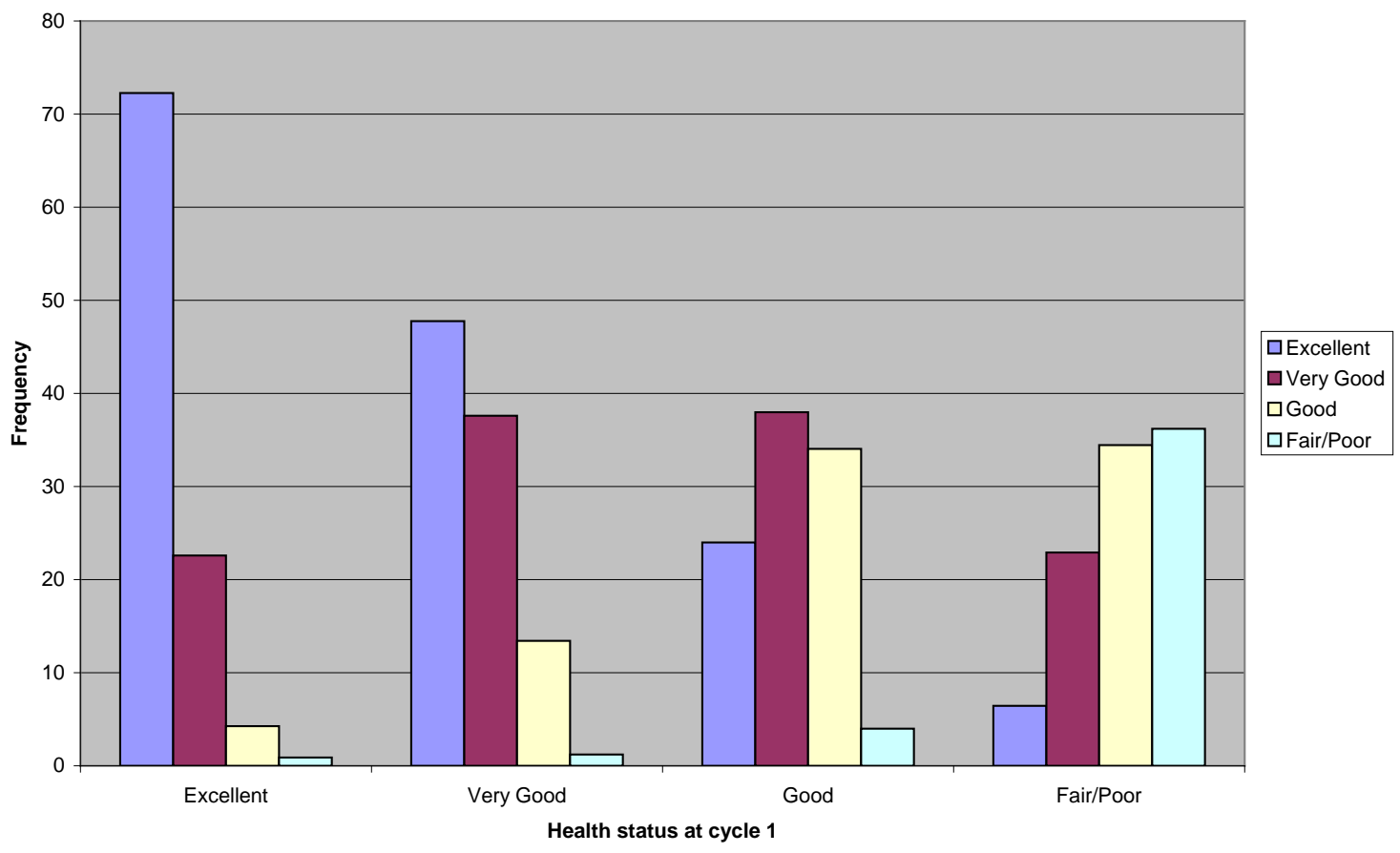


Figure 7. Predicted conditional probabilities of different child health scenarios based on random effects model

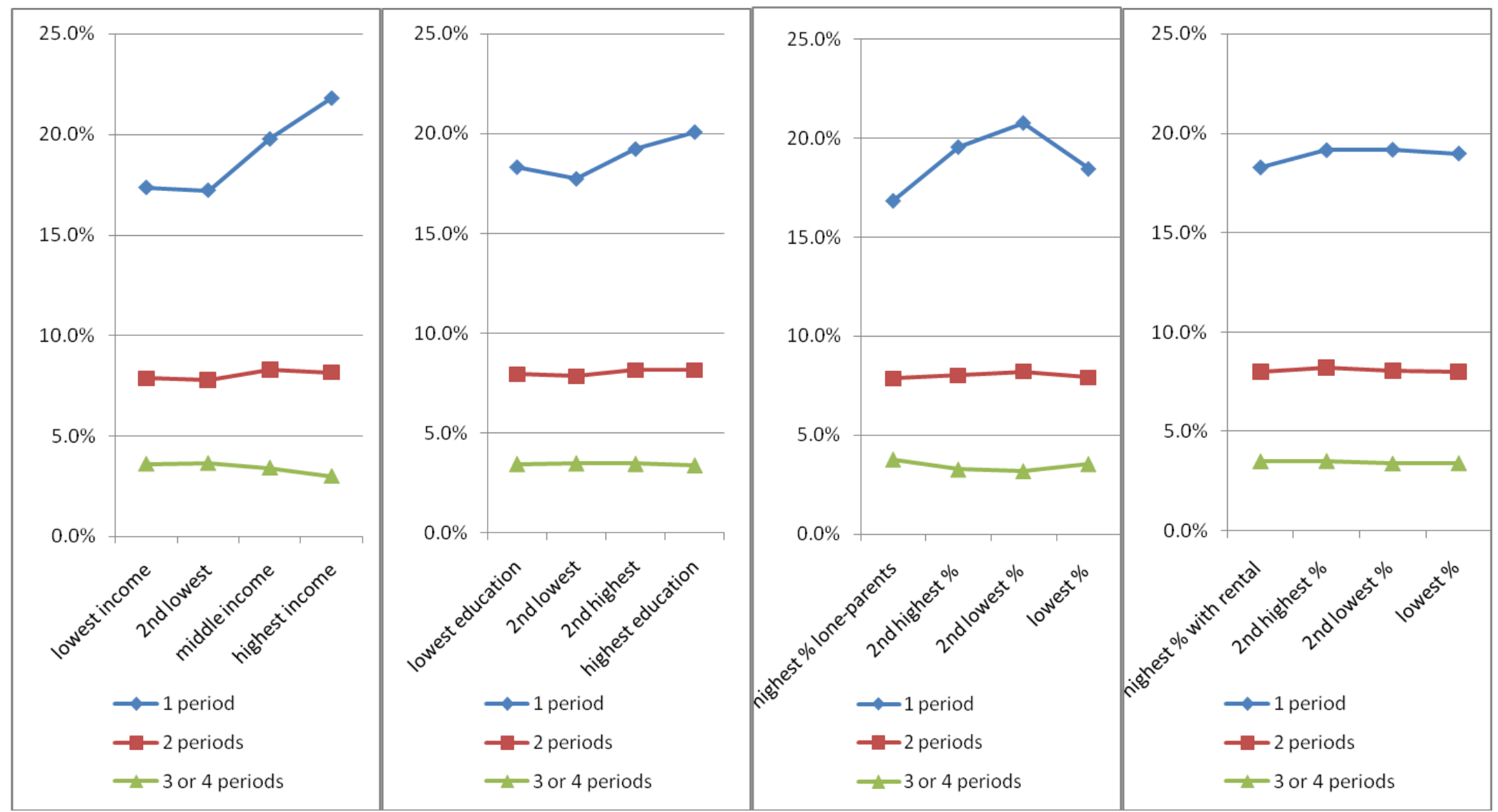

Note: in each panel on the x-axis, 1, 2, 3, 4 indicate the lowest rank, the second lowest rank, the second highest rank and the highest rank of neighborhood environment, respectively. 
Figure 8. Predicted conditional probabilities of different child health scenarios based on random effects model

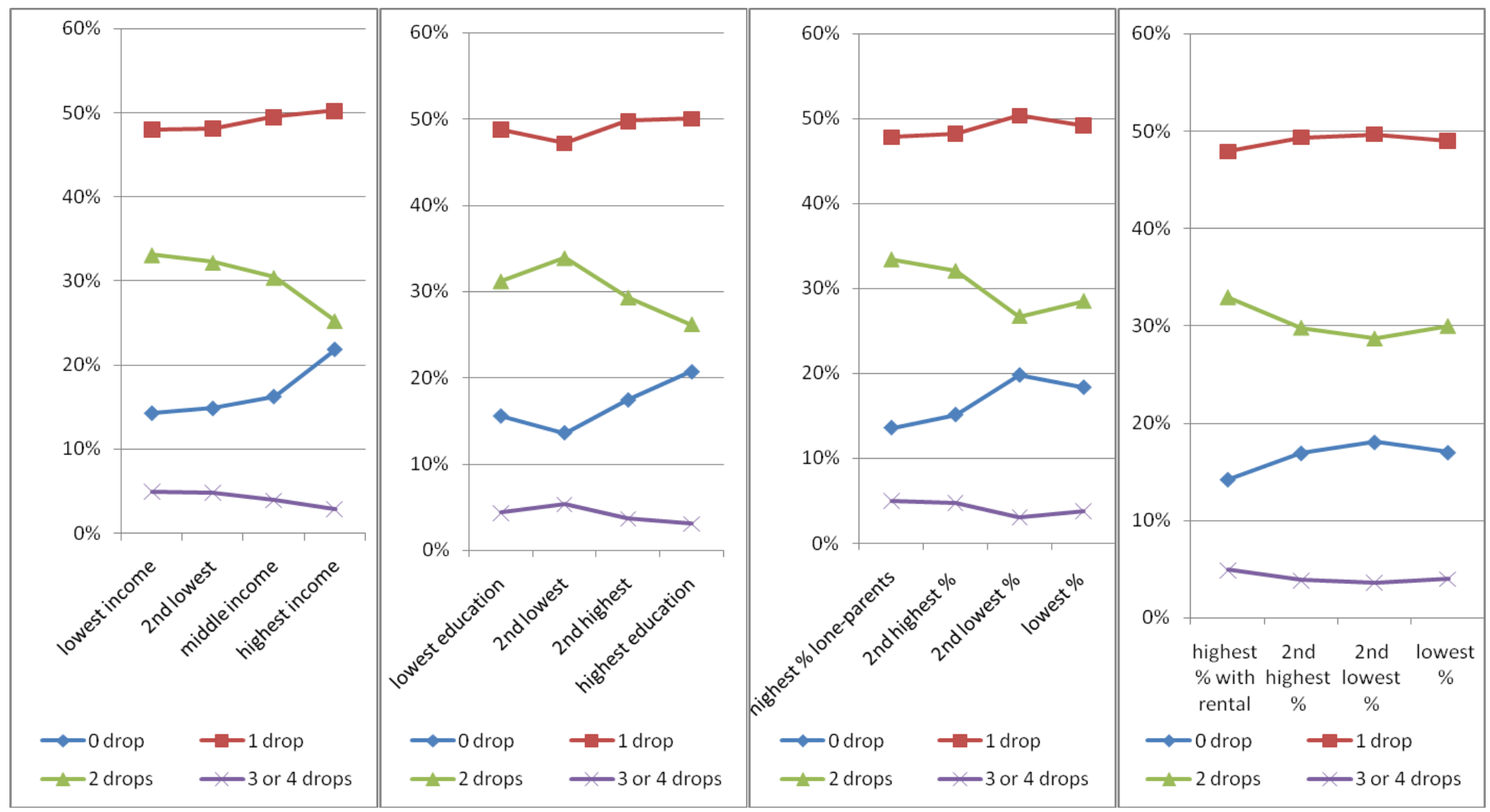

Note: in each panel on the x-axis, 1, 2, 3, 4 indicate the lowest rank, the second lowest rank, the second highest rank and the highest rank of neighborhood environment respectively. 
